Solvent Welding and Imprinting Cellulose Nanofiber Films Using lonic Liquids

\title{
Reyes, Guillermo
}

2019-01

Reyes , G , Borghei , M , King , A W T , Lahti , J \& Rojas , O J 2019 , ' Solvent Welding and Imprinting Cellulose Nanofiber Films Using lonic Liquids ', Biomacromolecules, vol. 20 , no. pÿ1 , pp. 502514 . https://doi.org/10.1021/acs.biomac.8b01554

http://hdl.handle.net/10138/307403

https://doi.org/10.1021/acs.biomac.8b01554

acceptedVersion

Downloaded from Helda, University of Helsinki institutional repository.

This is an electronic reprint of the original article.

This reprint may differ from the original in pagination and typographic detail.

Please cite the original version. 


\section{Solvent welding and imprinting cellulose nanofiber}

\section{films using ionic liquids}

Guillermo Reyes ${ }^{*}+$, Maryam Borghei ${ }^{\mathrm{L}}$, Alistair W. T. King ${ }^{\S}$, Johanna Lahti ${ }^{\ddagger}$, Orlando J. Rojas ${ }^{\ddagger}$.

† Departamento de Ingeniería en Maderas DIMAD, Universidad del Bío-Bío, Av. Collao 1202, Casilla 5-C, Concepción, Chile

$\${ }^{\mathrm{L}}$ Biobased Colloids and Materials, Department of Bioproducts and Biosystems, School of Chemical Engineering, Aalto University, Espoo, Finland

${ }^{\S}$ Materials Chemistry, Department of Chemistry, University of Helsinki, Helsinki, Finland

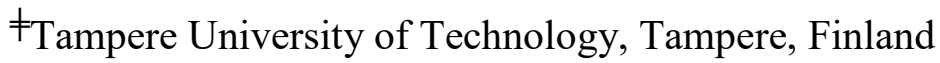

KEYWORDS: nanopaper imprinting, ionic liquids, welding, green chemistry

ABSTRACT: Cellulose nanofiber films (CNFF), were treated via a welding process using ionic liquids (ILs). Acid-base conjugated ILs derived from 1,5-diazabicyclo[4.3.0]non-5-ene [DBN] and 1-ethyl-3-methylimidazolium acetate ([emim][OAc]) were utilized. The removal efficiency of ILs from welded CNFF was assessed using liquid-state nuclear magnetic resonance (NMR) spectroscopy and Fourier transform infrared spectroscopy (FTIR). The mechanical and physical properties of CNFF indicated surface plasticization of CNFF, which improved transparency. Upon 
treatment, the average CNFF toughness increased by $27 \%$ and the films reached a Young modulus of $\sim 5.8 \mathrm{GPa}$. These first attempts for IL 'welding' show promise to tune bio-based films surfaces, expanding the scope of properties for the production of new bio-based materials in a green chemistry context. The results of this work are highly relevant to the fabrication of CNFFs using ionic liquids and related solvents.

\section{INTRODUCTION}

Globally, industries dedicated to the large-scale production of materials in fields such as construction, food, transport, pharmaceuticals, among others, are awakening to the problems caused by unsustainable processes, motivating a new focus to forest resources as a platform for radical innovations based on biomaterials ${ }^{1}$. In this context, a new family of materials based on cellulose, cellulose nanomaterials (CNMs), having properties and functionalities distinct from dissolved cellulose and wood fibers, are being developed for applications that were once thought impossible for cellulosic materials. Research and development of CNMs spans across various application areas including adhesives, cements, inks, drilling fluids, polymer reinforcement, nanocomposites, transparent films, layer-by-layer films, paper products, cosmetics, barrier/separation membranes, transparent-flexible electronics, batteries, supercapacitors, catalytic supports, continuous fibers and textiles, food coatings, healthcare, antimicrobial films, biomedical and tissue engineering scaffolds, $\mathrm{pH}$-responsive $\mathrm{CNMs}$, drug delivery, among others ${ }^{2}$. The sustainable preparation of cellulose-based nanomaterials is techno-economically challenging since this requires a low energy consumption process without the use, or production of, hazardous chemicals. The benefits are the production of high mechanical performance fibers and films, which 
have potential applications as textiles, support for particles, and as composite materials for catalytic and electrochemical applications ${ }^{3}$. Nanocellulose can form self-standing, thermallystable films and "nano-papers", thus this material has been strongly advocated as potential replacement for traditional packaging materials, primarily based on glass, aluminum, and fossilderived synthetic plastics ${ }^{4-16}$, but in many cases, such applications require an improvement of their physical and mechanical properties, in order to enhance their use ${ }^{13,17}$. At this respect, the novel concept of welding has been introduced by Haverlhals ${ }^{18-21}$. In this process, the surface of adjacent natural fibers (cotton, silk, and hemp) is plasticized and merged to create a congealed network using ILs such as 1-ethyl-3-methylimidazolium acetate ([emim][OAc]), a well-known cellulose-dissolving ionic liquid (IL).

The welding process is intended mainly for cellulosic and protein-based fibers with the purpose to improve mechanical properties, synthesis of composites and functionalization of materials ${ }^{18,22}$. The welding procedure has been used for modifying mainly cellulose macrofibers (not hydrolyzed neither treated fibers) to produce electrodes, catalysts, materials with special magnetic and electric features ${ }^{23,24}$, and synthesis of composites with improved mechanical properties ${ }^{25}$. The same concept, using N-methylmorpholine-N-oxide (NMMO), was used by Orelma ${ }^{26}$ to improve the mechanical performance of nanocellulose films.

The welding and plasticization of cellulose fibers can be seen as a partial dissolution process; therefore the understanding of the crucial factors in cellulose dissolution using ILs are fundamental. Experimental and computational results have shown that disruption of H-bonds inside cellulose is the critical factor in the dissolution process, the structural features of cellulose hydroxyl groups facilitate strong H-bonds with anions of ILs, even much stronger than the original H-bond network inside the cellulose structure ${ }^{27}$. In this regard, ILs containing chloride $[\mathrm{Cl}]$ and 
acetate $[\mathrm{OAc}]$ anions are widely used for cellulose dissolution ${ }^{28}$. Chloride-containing ILs solubilize cellulose through the establishment of hydrogen bonds; meanwhile, for ILs containing acetate anions the hydrogen bonding is accompanied by the conjugation of cellulosic reducing ends (at $\mathrm{C} 2$ for imidazolium cation); therefore, the anion and cation have shown to possess a synergistic effect ${ }^{27-31}$. The more basic acetate containing ILs reacts with oligocellulose reducing end groups to a much greater extent than the homologous ILs containing the chloride anion, suggesting that this reaction is likely dependent on the basicity of the anion ${ }^{32}$. This analysis conducted our attention to the basic ILs $[\mathrm{DBNH}][\mathrm{OAc}],[\mathrm{DBNH}]\left[\mathrm{CO}_{2} \mathrm{Et}\right]$, these ILs with high volatility, suggest an affordable new generation of ionic liquids that are both capable of dissolving cellulose and recyclable by distillation ${ }^{29,33}$.

In the present work, cellulose nanofibres are treated for the first time with ILs. The welding procedure is applied to aim the mechanical properties enhance and promote nanocellulose surface patterning. Even though some previous works report the welding surface treatment for natural and cellulose-based fibers and films ${ }^{18,22-24,26}$ and more recently the use of ILs for improving transparency and mechanical performance in microfibers and papers based materials ${ }^{34,28}$, the present work presents the treatment of nanofibrillated surfaces using distillable ILs; these ILs in contrast to the traditional ILs can be recyclable by distillation with recoveries and purities over $99 \%{ }^{29,36}$. Distillable ionic liquids are ILs that can be recovered by distillation. This approach takes advantage of the IL recyclability and additionally as it is shown in the following results, the treatment only occurs at the surface level, since it acts over a nanofibrillated structure that is supposed to be more packed and densified compared to that in microfibrillated materials. The ILs tested were not able to penetrate in the structure of nanopaper, thus avoiding the modification of the films at the bulk level and therefore avoiding the capture of IL molecules inside the fibrillar 
network, placing those molecules only onto the surface where they can be easily removed. As a consequence, the washing process is simplified to a couple of washing steps, guaranteeing the absence of ILs, an essential aspect, especially if these materials are thought to be used in the food industry applications.

Films (CNFFs) are prepared through filtration and hot-pressing processes. The films are welded individually using the acid-base conjugate ILs 1,5-diazabicyclo[4.3.0]non-5-enium propionate $\left([\mathrm{DBNH}]\left[\mathrm{CO}_{2} \mathrm{Et}\right]\right)$ and 1,5-diazabicyclo[4.3.0]non-5-enium acetate ([DBNH][OAc] $)$, due to their

ability to dissolve cellulose, low cost and potential for recycling by distillation ${ }^{29,36}$. It is important to notice that even though there are several works reported on welding, the welding process has been widely reported for macrofibres (papers, fabrics) using [emim][OAc] ${ }^{18-21}$, thus, this IL was used for comparison purposes. The impregnation and diffusion behavior of ILs into individual CNFFs were characterized using optical microscopy, contact angle (CA), scanning electron microscopy (SEM), Fourier-transform infrared (FTIR) spectroscopy, ultraviolet-visible (UV-Vis) spectroscopy, nuclear magnetic resonance (NMR) spectroscopy and X-ray diffraction (XRD) measurements. The mechanical performance of individual impregnated films was tested using a tensile tester.

\section{MATERIALS AND METHODS}

Films production. Birch kraft pulp (BKP) from a Finnish pulp mill (UPM, kappa number 1; DP 4700; fines-free) was microfluidized (6 passes at 2000 bar, Microfluidics M-110PTM, International Corporation, USA). Figure Sa1 (see the supporting information) shows atomic force microscopy (AFM) image of the microfluidized fibrils. The nanofibrillated material possesses a length in the scale of microns and an average diameter of $37 \pm 9 \mathrm{~nm}$. The fibrils were diluted to a $0.1 \%$ solids 
content by adding Milli- ${ }^{\circledR}$ water (Merck-Millipore). From this suspension, 750 grams were used for the preparation of circular films.

The system used for CNFF preparation is analogous to the system used for paper sheet preparation. After dilution, the sample was agitated vigorously in a magnetic stirrer (12 hours), sonicated three times for 5 minutes, each at 30\% power amplitude inside an ice bath (Branson Digital Sonifier, Branson Ultrasonics Sonifier ${ }^{\mathrm{TM}}$ S-250D Digital Ultrasonic Cell Disruptor/Homogenizer), filtered in a home-made filter, as it is shown in Figures S2a-S2d.

The filter, integrated by a tripod chamber (inner diameter of $12 \mathrm{~cm}$, height $8.5 \mathrm{~cm}$ ) allows for the preparation of the hydrogel cake, after air pressure filtration at 4 bar, $1.5 \mathrm{~h}$ (see Figure Sa2, see the supporting information). The hydrogel-like cake was obtained above the filters (see Figure Sa2b). The filters are composed by polyvinylidene fluoride (PVDF) membrane filter (Durapore ${ }^{\circledR}$, $142 \mathrm{~mm}$ diameter, $0.22 \mu \mathrm{m}$ pore size, REF GVWP14250, Merck Millipore ${ }^{\odot}$ ), and a Schleicher \& Schüll Rundfilter (150 mm diameter, Whatman ${ }^{\mathrm{TM}}$, Ref. No. 300212) underneath. The CNFF films preparation, involves a drying step by hot pressing, using several layers configuration as it is detailed in Figure Sa2c, between two aluminum plates each side composed as follows: three layers of strawboard, four layers of regular bond paper, one layer of SEFAR NITEX ${ }^{\circledR}$ fabric, code: 03 $1 / 1$ and one membrane filter on top (the same filter used for filtration). After the filtration, the cake was hot pressed in a Carver Laboratory Press 18200-213 (Figure Sa2d) made by Freds. Carver Inc. Hydraulic equipment, NJ, USA. The samples were hot pressed $\left(2 \mathrm{kN} / \mathrm{cm}^{2}, 100^{\circ} \mathrm{C}, 50 \mathrm{~min}\right)$, obtaining circular films with a diameter of $120 \mathrm{~mm}$ and thickness around $50 \mu \mathrm{m}$. As it is shown in Figure Sa2b (see the supporting information), the films prepared exhibited the characteristic translucency of films composed by nanofibers ${ }^{37}$. 
Chemicals and reagents. CNFF were welded using three ILs [emim][OAc], CAS No. 143314$17-4$, purity $>95 \%$ was purchased from Basionic ${ }^{\mathrm{TM}} ; \quad[\mathrm{DBNH}]\left[\mathrm{CO}_{2} \mathrm{Et}\right]$ was synthesized from its precursors 1,5-diazabicyclo[4.3.0]non-5-ene (DBN), CAS No. 3001-72-7, purity = 99\%, Fluorochem U.K.; propionic acid, CAS No. 79-09-4, purity > 99\%, Sigma Aldrich ${ }^{\circledR}$; $[\mathrm{DBNH}][\mathrm{OAc}]$ was synthesized from its precursors using acetic acid, CAS No. 64-19-7, purity > 99.8\%, Sigma Aldrich ${ }^{\circledR}$. [DBNH] ILs preparation was made as reported previously ${ }^{38}$. Table Sa1 (see the supporting information) summarizes the reagents used in the present study. [DBNH][OAc] $\left(\mathrm{mp} 63{ }^{\circ} \mathrm{C}\right.$ ) was mixed with 5\% w/w of gamma-valerolactone (GVL) (CAS No. 108-29-2, purity $>98 \%$, Sigma Aldrich ${ }^{\circledR}$ ) to render the IL into liquid form at room temperature, for handling purposes. $[\mathrm{DBNH}]\left[\mathrm{CO}_{2} \mathrm{Et}\right]$ was used as prepared, as it was already a room temperature ionic liquid (RTIL). DMSO-d 6 for ${ }^{1} \mathrm{H}$ NMR experiments was purchased from Sigma Aldrich (CAS No. 220627-1, purity 99.96 atom \%D), IL electrolyte tetrabutylphosphonium acetate $\left[\mathrm{P}_{4444}\right][\mathrm{OAc}]$ was prepared according to Holding ${ }^{39}$.

All the ILs were vacuum dried overnight $\left(60^{\circ} \mathrm{C}, 200 \mathrm{mbar}\right)$ to remove any water molecules condensed during the synthesis process. To remove the ILs from the CNFF after welding, ethanol CAS no. 64-17-5, analytical standard from Sigma Aldrich ${ }^{\circledR}$, and Milli $\mathrm{Q}^{\circledR}$ type I water, ultrapure water Merck, ${ }^{\odot}$ were used. CNFF samples were stored at $50 \%$ relative humidity room before the welding procedure.

Films welding. The welding procedure consists of four basic steps: 1) impregnation with respective IL, 2) hot-press activation, 3) washing (to remove IL), and 4) hot-press drying (see Figure 1). 

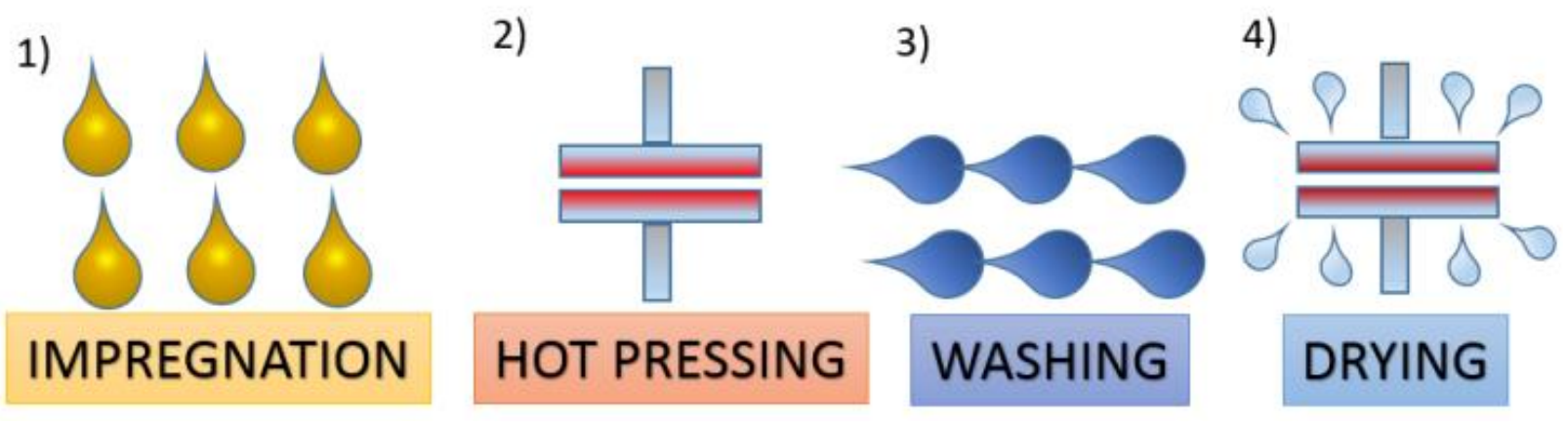

Figure 1. Basic welding procedure steps

Before welding, the CNFFs were pre-dried under vacuum $\left(200 \mathrm{mbar}, 60^{\circ} \mathrm{C}, 12 \mathrm{~h}\right)$. The first step involves the complete impregnation of the material with the corresponding ILs $\left([\mathrm{DBNH}][\mathrm{OAc}]: \mathrm{GVL}(95: 5 \mathrm{w} / \mathrm{w}),[\mathrm{emim}][\mathrm{OAc}]\right.$, and pure $\left.[\mathrm{DBNH}]\left[\mathrm{CO}_{2} \mathrm{Et}\right]\right)$. For this step, the CNFFs were immersed in enough IL amount to wet the surface completely ( $\sim$ grams of IL), and after this, the wet CNFF was placed between two glass slides for two minutes at ambient conditions. It is important to notice that ILs usually tolerate water contents around 7\% ${ }^{40,41}$ and theoretically ${ }^{31}$ up to $20 \% \mathrm{w} / \mathrm{w}$ and still can dissolve cellulose; in this work the ILs were dried before its use (as mentioned previously) so the water influence on the welding procedure is minimized considering this and the short time of exposure to ambient conditions.

The second step involves the hot pressing of the impregnated films $\left(2 \mathrm{kN} / \mathrm{cm}^{2}, 100^{\circ} \mathrm{C}, 5 \mathrm{~min}\right)$ using a SEFAR (SEFAR NITEX ${ }^{\circledR}$ fabric, code: 03-1/1) covering each face. The third step consists of washing away the residual IL submerging the film for five minutes under agitation initially in pure water (Milli $\left.\mathrm{Q}^{\circledR}\right)$. The same procedure is then repeated with ethanol (99\% purity) and finally with water. Each washing procedure was repeated three times to guarantee the complete removal of the ILs. The [DBNH] derived ILs can be recovered by distillation from the water/ethanol/ IL mixture, for details about distillation process readers are referred to available reported methods 
29,33. Finally, step four considers a drying procedure using the same protocol used in step two (hot pressing, with SEFAR fabrics).

\section{Instrumental methods}

Optical Microscope. Optical light microscope images were obtained using a microscope Leica DM 750 Microsystems ${ }^{\circledR}$, Germany, camera ICC50HD. The samples were placed between two glass slides, and the light was adjusted using an external source of light, Lampe Fiber Optic Fi. L100.

Fourier-Transform Infrared Spectroscopy (FT-IR). Characterization was conducted with a Thermo Fisher Scientific Nicolet Avatar 380 FTIR spectrometer in transmittance mode using tips for solid/films samples. Samples were vacuum dried for $16 \mathrm{~h}$ before the test. Spectra were acquired for 32 scans in the range from 500 to $4000 \mathrm{~cm}-1$ wave number range with a resolution of $2 \mathrm{~cm}-1$.

Contact Angle. The static Water Contact Angle (WCA) Os, was measured in a custom-built system equipped with a KSV Instruments camera and software CAM 200 Digital Contact Angle Meter. A droplet of $\sim 6.5 \mu \mathrm{l}$ was deposited in four different locations in each sample, and each droplet contact angle was recorded for 30 seconds with a resolution of 0.02 seconds.

UV-Vis. Transmittance experiments were conducted in a wavelength range of $300 \mathrm{~nm}$ until 800 $\mathrm{nm}$ with a resolution of $1 \mathrm{~nm}$ using the UV-Vis spectrophotometer Cary $5000 \mathrm{UV}$-Vis-NIR Spectrophotometer, Agilent Technologies, USA. The transmittance was measured at three different positions on the sample $(1.5 \mathrm{~cm} \times 1.5 \mathrm{~cm}$ CNFFs $)$ being the final transmittance, the average transmittance of those measurements.

Scanning Electron Microscopy (SEM). Surface morphology of the CNFFs was assessed using SEM (ZEISS SIGMA VP, Germany). Before imaging, samples were vacuum dried for $18 \mathrm{~h}$ 
overnight and subsequently sputtered with an $\sim 7 \mathrm{~nm} \mathrm{Au/Pt} \mathrm{layer} \mathrm{(Emitech} \mathrm{K100X).} \mathrm{The} \mathrm{images}$ were analyzed using ImageJ ${ }^{42}$.

Atomic Force Microscopy (AFM). The CNF morphology used for CNFF preparation was analyzed using AFM (Digital Instruments Multimode Atomic Force Microscope, Bruker, UK). The samples were deposited on a silica wafer and analyzed at room temperature $\left(23^{\circ} \mathrm{C}\right)$, operating in tapping mode.

Tensile Test. The mechanical properties of the CNFFs were evaluated using a Universal Tensile Tester Instron 4204, with $1 \mathrm{kN}$ load cell. The samples were prepared according to the ASTM D63803 standard. All the samples were stored before the test in a conditioned room at $50 \%$ R.H, $23^{\circ} \mathrm{C}$. For the tests they were cut into small strips of $5.3 \mathrm{~mm} \times 20 \mathrm{~mm}$ and fixed to the Instron clamps, using printer paper to hold the strip sides and gluing them with Loctite ${ }^{\circledR}$ super glue. The thickness of the samples was measured using a micrometer (Lorentzen and Wettre Micrometer, Sweden) and repeated ten times in different positions; then the results were averaged. Six replicas of each sample were taken for the mechanical tests, and the results were averaged.

X-ray Diffraction $(X R D)$. Crystallinity index and crystallite sizes were obtained, using an X-ray diffractometer Rigaku Smartlab®, equipped with a single-photon counter HyPix-3000. The beamsize was controlled with one horizontal slit of $10 \mathrm{~mm}$, in the transmittance mode using parallel beam. Approximately $0.05 \mathrm{~g}$ was used for each experiment on the sample holder. Angular scanning was conducted from 5 to $50^{\circ}$ at $5 \%$ min with $\mathrm{Cu} \mathrm{K \alpha}$ radiation (1.54059 $\AA$ ). The generator was working at $45 \mathrm{kV}$ and $200 \mathrm{~mA}$. Background correction due to sampler holder and the air was made by subtracting the sample diffractogram data with the corresponding blank data (without CNFF). The crystallinity analysis of the CNFFs was performed according to literature procedures ${ }^{43-45}$. Table Sa2 (see the supporting information) shows the diffractometer angles for cellulose I and II 
with their respective Miller indices. This information was used to identify which peaks were present to decide upon the deconvolution procedure. The deconvolution procedure was initially performed using fityk ${ }^{46}$ curve fitting and data analysis software. Gaussian functions were fitted, later the graphing and data analysis software Origin ${ }^{\circledR}$, OriginLab (Licensed by Aalto University, Espoo, Finland), was used for further plotting and calculations procedures. The crystallite size, $\tau(\AA)$, perpendicular to the lattice planes for cellulose I was calculated by the Scherrer equation 47.

$$
\tau=\frac{K \lambda}{\beta \cos \theta}
$$

Where $\mathrm{K}$ is the Scherrer constant (0.94), $\lambda$ is the wavelength of the $\mathrm{X}$-ray radiation (1.54059 $\AA$ ), and $\beta$ is the FWHM (Full width at half maximum) of the diffraction peak in radians, and $\theta$ is the diffraction angle of the peak.

The Segal crystallinity index (CI), was calculated according to the following equation ${ }^{48}$ :

$$
C I=\frac{I_{t}-I_{a}}{I_{t}} * 100
$$

Where $I_{t}$ is the total intensity of the $\left(\begin{array}{lll}0 & 0\end{array}\right)$ peak for cellulose $I$ and $I_{a}$ is the intensity assigned to the amorphous cellulose.

Nuclear Magnetic Resonance. All NMRs were performed on a Varian ${ }^{\mathrm{UNITY}}$ INOVA $600 \mathrm{MHz}$ NMR spectrometer with a $5 \mathrm{~mm}$ triple resonance gradient probehead. The IL purities were checked by dissolving samples in fresh DMSO-d $\mathrm{d}_{6}$ and running ${ }^{1} \mathrm{H}$ spectra. Identification of ${ }^{1} \mathrm{H}$ and ${ }^{13} \mathrm{C}$ resonances for anhydroglucose unit (AGU) and anhydroxylose unit (AXU) species were determined through heteronuclear single quantum coherence (HSQC) spectroscopy and total correlation spectroscopy (TOCSY) on untreated (dried) BKP CNFF (5 wt $\%$ ) in the ionic liquid electrolyte tetrabutylphosphonium acetate $\left(\left[\mathrm{P}_{4444}\right][\mathrm{OAc}]\right): \mathrm{DMSO}_{-} \mathrm{d}_{6}(1: 4 \mathrm{w} / \mathrm{w}){ }^{49}$. Similarly, 
quantitative ${ }^{1} \mathrm{H}$ and diffusion-edited ${ }^{1} \mathrm{H}$ spectra were run on the IL-treated CNFFs in the same electrolyte. The full conditions for dissolution and analysis are given in the supporting information (See supporting information_B). Diffusion-edited ${ }^{1} \mathrm{H}^{49}$ was used to distinguish between the high and low molecular weight species in the sample, as the method filters out the low molecular weight species (ionic liquid and DMSO) from the spectra. Residual [emim][OAc] was quantified in the

sample by integration of the $\mathrm{C} 4 \& \mathrm{C} 5$ peaks region against the $\left[\mathrm{P}_{4444}\right][\mathrm{OAc}] \partial$-Me (as internal standard). See supporting information for more details about ${ }^{1} \mathrm{H}$ NMR procedure.

Barrier properties. Oxygen Transmission Rate (OTR) barrier properties were measured using a Mocon Ox-Tran 2/21 MH/SS (Laboratory of Material Science, Paper Converting and Packaging Technology, Tampere University of Technology). Samples were prepared according to the ASTM D3985-05 standard method. The oxygen barrier was measured using two different replicas from the same sample $(23 \mathrm{C} / 50 \% \mathrm{RH})$ dimensions $5 \mathrm{~cm} \times 5 \mathrm{~cm}$. Water Vapor Transmission Rate (WVTR) was obtained using the cup test, according to the ASTM E96 standard method.

\section{RESULTS AND DISCUSSION}

Surface chemical composition. The welding procedure comprises a final washing step that is intended to remove all the IL that is remaining after the hot activation; this is necessary due to the potential cost and toxicity of the ionic liquids. Some ILs have shown an important toxicity degree, especially hydrophobic and long side chain substituted ILs can destroy the cell membrane and act as neurotoxins ${ }^{50}$. Therefore the presence of any residual IL should be avoided. However, initial toxicity results suggest there are no major toxicity issues with the IL [emim][OAc] and DBNderived carboxylate ionic liquids ${ }^{51-53}$. In addition, the IL welded CNFFs have changed their UVVis transmittance, suggesting that in some cases, IL might also remain attached to the films. 
Therefore, it is necessary to apply suitable analytical methods to monitor the removal of the IL. In this case, the CNFF chemical compositions were assessed using FTIR, as a rapid technique and a novel liquid-state NMR method involving the dissolution of the films into IL electrolyte solution ${ }^{49}$, and XRD measurements. Figure 2 shows the FTIR spectra of the untreated and IL welded sample.

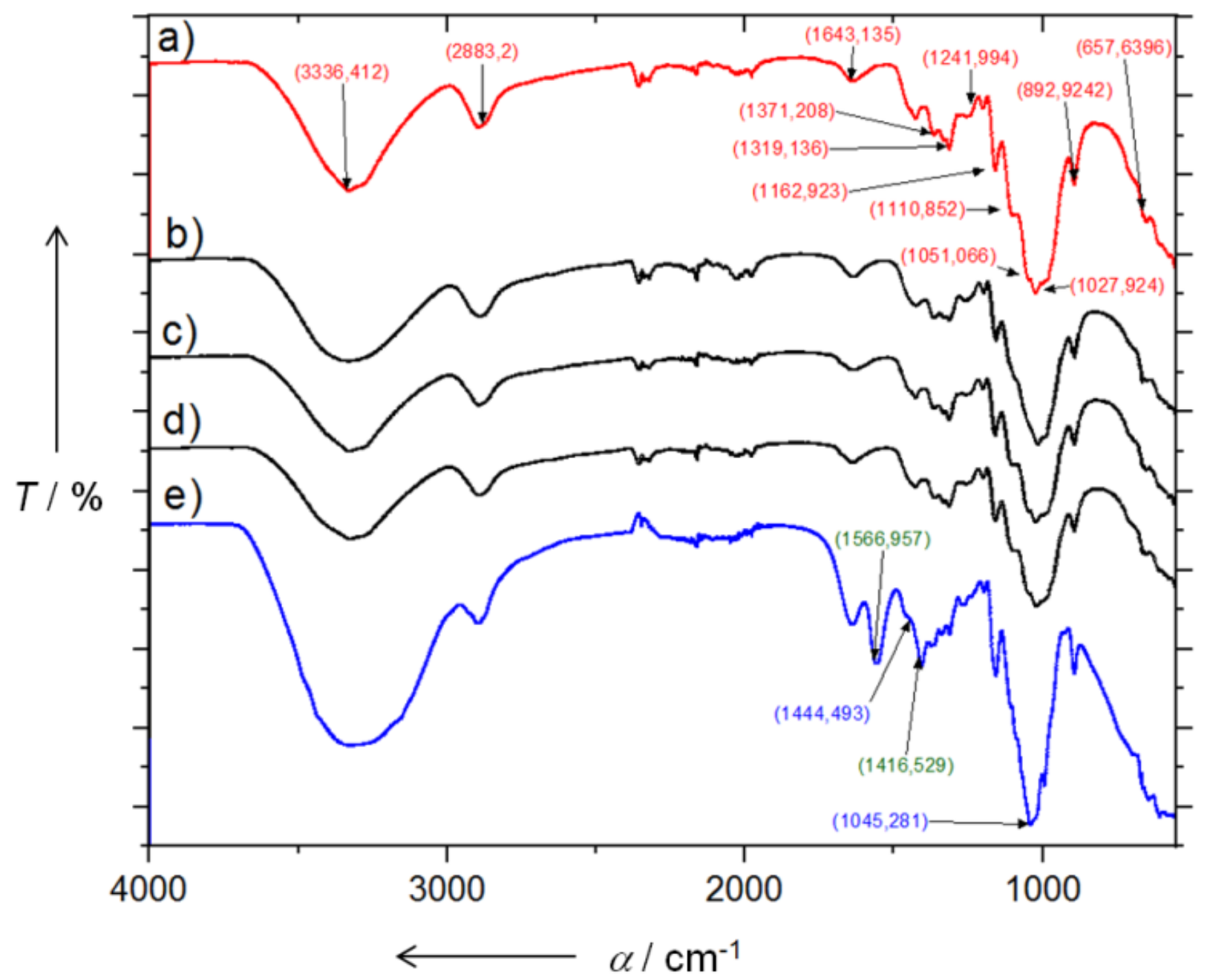

Figure 2. FTIR spectra for the CNFFs: a) untreated, b) [emim][OAc] welded, c) [DBNH][OAc] welded, d) $[\mathrm{DBNH}][\mathrm{CO} 2 \mathrm{Et}]$ welded, e) CNFF regenerated with [emim][OAc] (no washing step) 
In Figure 2, $T$ represents transmittance and $\alpha$ wavenumber, lines in red and blue are the reference lines and represent untreated $\mathrm{CNF}$ and regenerated CNF with IL [emim][OAc], Figures $2 \mathrm{a}$ and $2 \mathrm{e}$ respectively.

Broadband peaks are observed for all samples around $3300 \mathrm{~cm}^{-1}$ corresponding to $(-\mathrm{OH})$ groups stretching vibrations (Figure 2a-2d), being more extensive for the regenerated cellulose (Figure 2e). After the broadband peak, it is possible to observe the peak at $2883 \mathrm{~cm}^{-1}$ assigned to $(\mathrm{C}-\mathrm{H})$ bond vibrations, presented in all samples ${ }^{54}$. The noisy signals between $2300-1900 \mathrm{~cm}^{-1}$ are an artifact of the equipment and were not assigned to any chemical group in the samples. It is possible to see a peak around $1640 \mathrm{~cm}^{-1}$ related to $(\mathrm{O}-\mathrm{H})$ bending vibration of the absorbed water ${ }^{54}$. Similar water peaks appeared for all samples, although they were dried in a vacuum oven $\left(200 \mathrm{mbar}, 60^{\circ} \mathrm{C}\right)$ overnight and stored in a desiccator, this was probably due to high hydrophilicity of CNFF samples after welding procedure, causing water molecules adsorption during sampling.

The peaks from 1371 and $660 \mathrm{~cm}^{-1}$ reveal that the samples exhibited almost identical FTIR spectra, comparing with the CNFFs untreated samples ${ }^{54-57}$ (Figures 2a-2d). Additionally for making more explicit the difference between the samples and regenerated CNF (Figure 2e) the regenerated sample exhibits one peak at $1045 \mathrm{~cm}^{-1}$ due to pyranose ring ether stretching vibration without the two additional small peaks around this peak, which are present in the case of cellulose type $I^{54,57}$. Finally the two peaks due to the presence of the Ionic liquid [emim][OAc] at $1415 \mathrm{~cm}^{-}$ ${ }^{1}$ due to $(\mathrm{C}-\mathrm{N})$ stretching, and $1565 \mathrm{~cm}^{-1}$ due to $(\mathrm{C}=\mathrm{N})$ stretching are absent in all samples indicating in principle that the washing step was effective in the removal of ILs ${ }^{58}$.

From the FTIR, it is clear that the cellulose on the surface of the film does not contain significant quantities of ionic liquid, due to the close similarity between the treated (Figures 2b-2d) and untreated samples (Figure 2a). Comparing with an example of a film with [emim][OAc] 
impregnated within (Figure 2e), the [emim] [OAc] welded CNFF (Figure 2b) does not show any peaks that might correspond to the presence of [emim][OAc]. While FTIR is a rapid method, it lacks resolution and thus sensitivity. Therefore, we applied a recently published method, liquidstate NMR for analysis of the bulk sample ${ }^{49}$. The method utilizes the IL electrolyte tetrabutylphosphonium acetate $\left(\left[\mathrm{P}_{4444}\right][\mathrm{OAc}]\right): \operatorname{DMSO}_{-} \mathrm{d}_{6}(1: 4 \mathrm{w} / \mathrm{w})$ for direct-dissolution of the films and subsequent quantitative ${ }^{1} \mathrm{H}$ NMR analysis (Figure 3).

a)
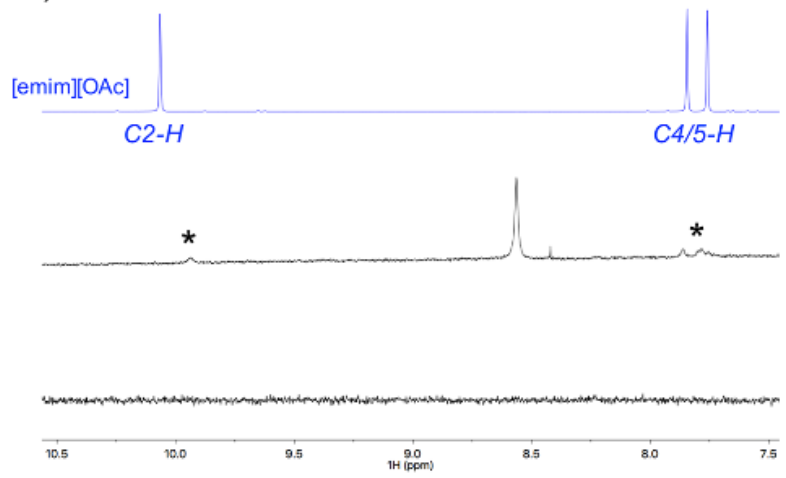

c)

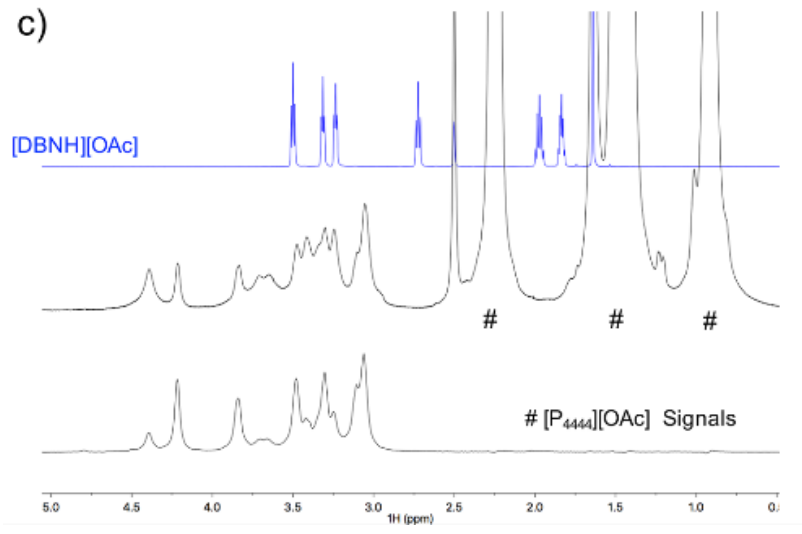

b)

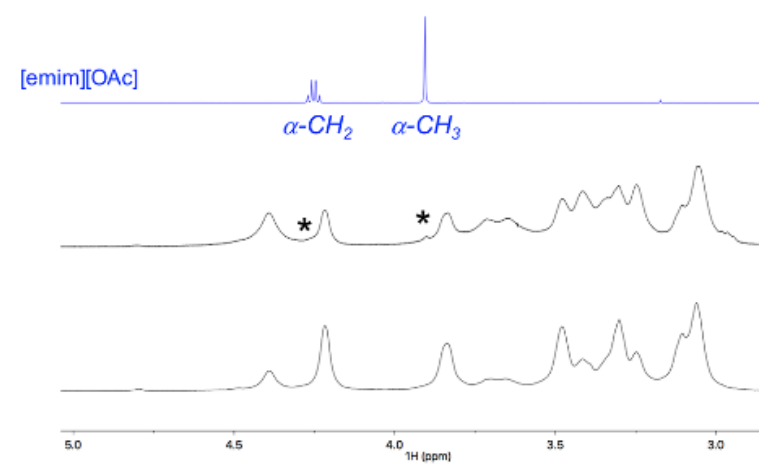

d)

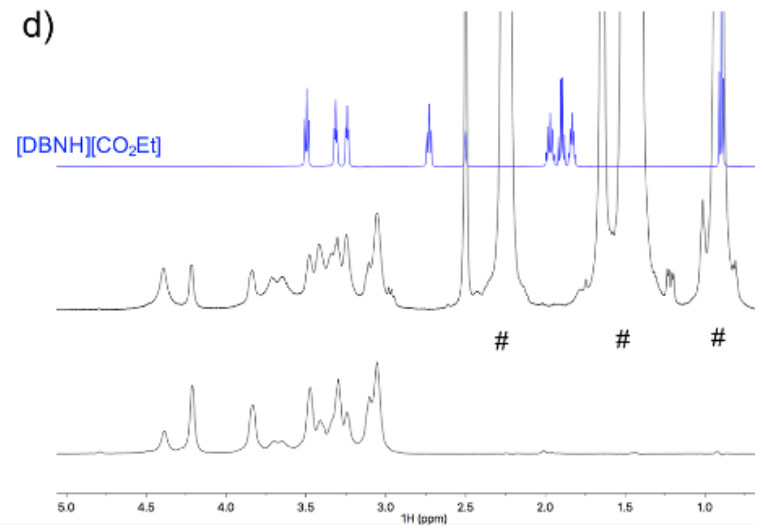

Figure 3. ${ }^{1} \mathrm{H}$ NMR analysis $(600 \mathrm{MHz})$ of the CNFFs dissolved in $\left[\mathrm{P}_{4444}\right][\mathrm{OAc}]: \mathrm{DMSO}_{-} \mathrm{d}_{6}(1: 4$ $\mathrm{w} / \mathrm{w})$ at $65^{\circ} \mathrm{C}$ : a) $[\mathrm{emim}][\mathrm{OAc}]$ welded (7.5-10.5 ppm), b) [emim][OAc] welded (2.5-5 ppm), c) [DBNH][OAc] welded, d) [DBNH][CO2Et] welded; Top spectra show the pure ILs, middle spectra shows the quantitative ${ }^{1} \mathrm{H}$ experiments and the bottom spectra show the diffusion-edited ${ }^{1} \mathrm{H}$ experiments (fast-diffusing species absent). 
Figure 3 compares the pure ILs in DMSO-d6 (top/blue spectra), against both the quantitative ${ }^{1} \mathrm{H}$ and diffusion-edited ${ }^{1} \mathrm{H}$ spectra for the dissolved CNFFs. Diffusion-editing, while not a quantitative experiment, has the effect of removing almost completely the fast-diffusion species from the spectra, i.e., the ILs and DMSO. The ${ }^{1} \mathrm{H}$ spectra for both [DBNH][OAc] (Figure 3c middle spectrum) and [DBNH][CO2Et] (Figure 3d - middle spectrum) clearly show an absence of peaks corresponding to any residual IL. However, the [emim][OAc] sample (Figure 3a,b) shows residual peaks corresponding to the imidazolium ring protons $(\mathrm{C} 2 / 4 \& 5$ positions, Figure $3 \mathrm{a})$ and the $\alpha$-alkyl on the imidazolium ring (Figure $3 b$ ). These are unmistakable and when the $\mathrm{C} 4 / 5-\mathrm{H}$ region is integrated against the $\partial-\mathrm{Me}$ on [P4444][OAc] (50 $\mathrm{mg}$ of CNFF vs $190 \mathrm{mg}$ of [P4444][OAc] in the NMR sample), a residual amount of $0.4 \mathrm{wt} \%$ can be calculated for [emim][OAc] left in the CNFF. While it is known that under certain conditions [emim] [OAc] can react with reducing ends in cellulose ${ }^{32,59}$, the diffusion-edited spectra does not show the presence of these peaks, indicating that the residual $[\mathrm{emim}][\mathrm{OAc}]$ is not conjugated with reducing ends, and its removal may be a matter of optimization of the washing conditions.

For assignment of the biopolymer peaks in the ${ }^{1} \mathrm{H}$ spectra, the untreated CNFF was also dissolved in the electrolyte. Heteronuclear single quantum coherance (HSQC) spectroscopy and total correlation spectroscopy (TOCSY) NMR analysis were performed identifying the peaks corresponding to the polymeric anhydroglucose units (AGU, cellulose) and anhydroxylose units (AXU, xylan) in the samples (see the supporting information B). As the resonances, derived from kraft pulp have not yet been assigned before using the $\left[\mathrm{P}_{4444}\right][\mathrm{OAc}]:$ DMSO- $\mathrm{d}_{6}$ solvent system, the assignments are presented in Table Sb1 (see the supporting information). The 2D peak assignments are entirely consistent with those for the ${ }^{1} \mathrm{H}$ experiments (Figure 3). 
Surface morphology. Samples were first photographed using a Canon 700D camera equipped with a Canon MP-E 65mm f/2.8 1-5x macro lens at full magnification and backlight illumination. Figure 4 reveals the surface morphology.
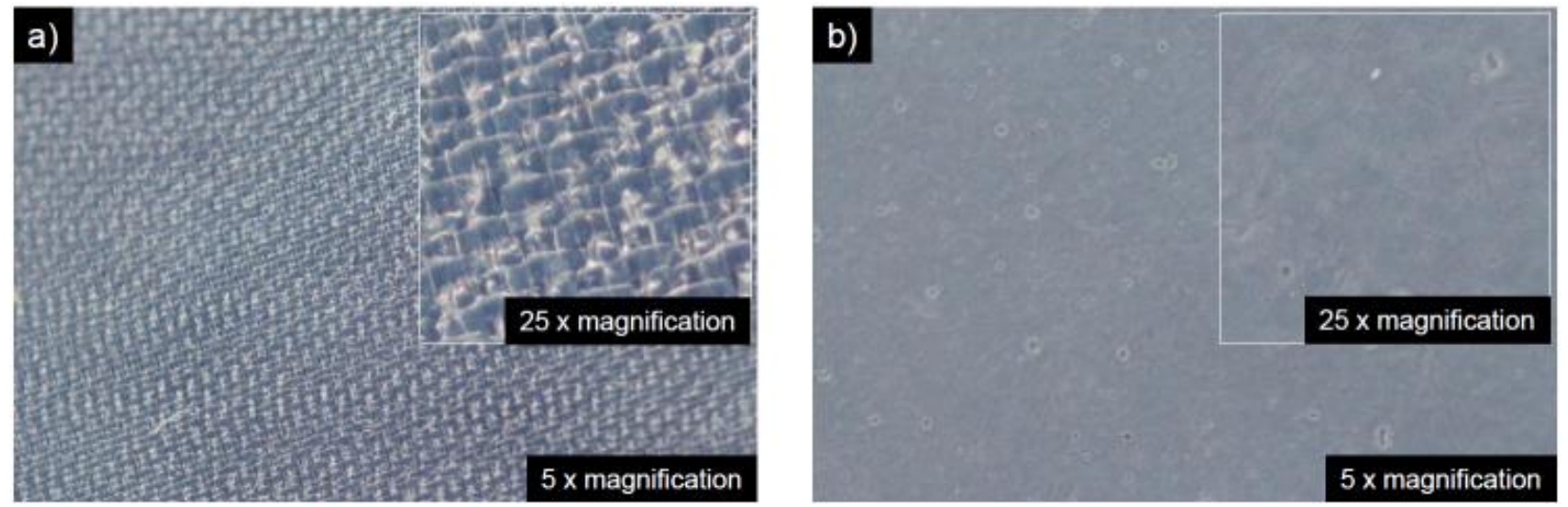

Figure 4. Macro photography images against a dark blue background, for CNFF samples: a) welded with [emim][OAc], b) untreated

Photography images of welded surfaces reveal a surface patterning after the welding procedure with [emim][OAc] (Figure 4). This patterning is produced by the plasticization of the surface depending on the IL type, as it was revealed in the optical microscopy images. Samples with dimensions of $5 \mathrm{~cm} \times 5 \mathrm{~cm}$ and thickness $=\mathrm{t}$ were analyzed with the optical microscope, and SEM (see Figure 5). It is important to point out that the untreated samples were processed the same way as the treated samples but in the absence of ILs. 

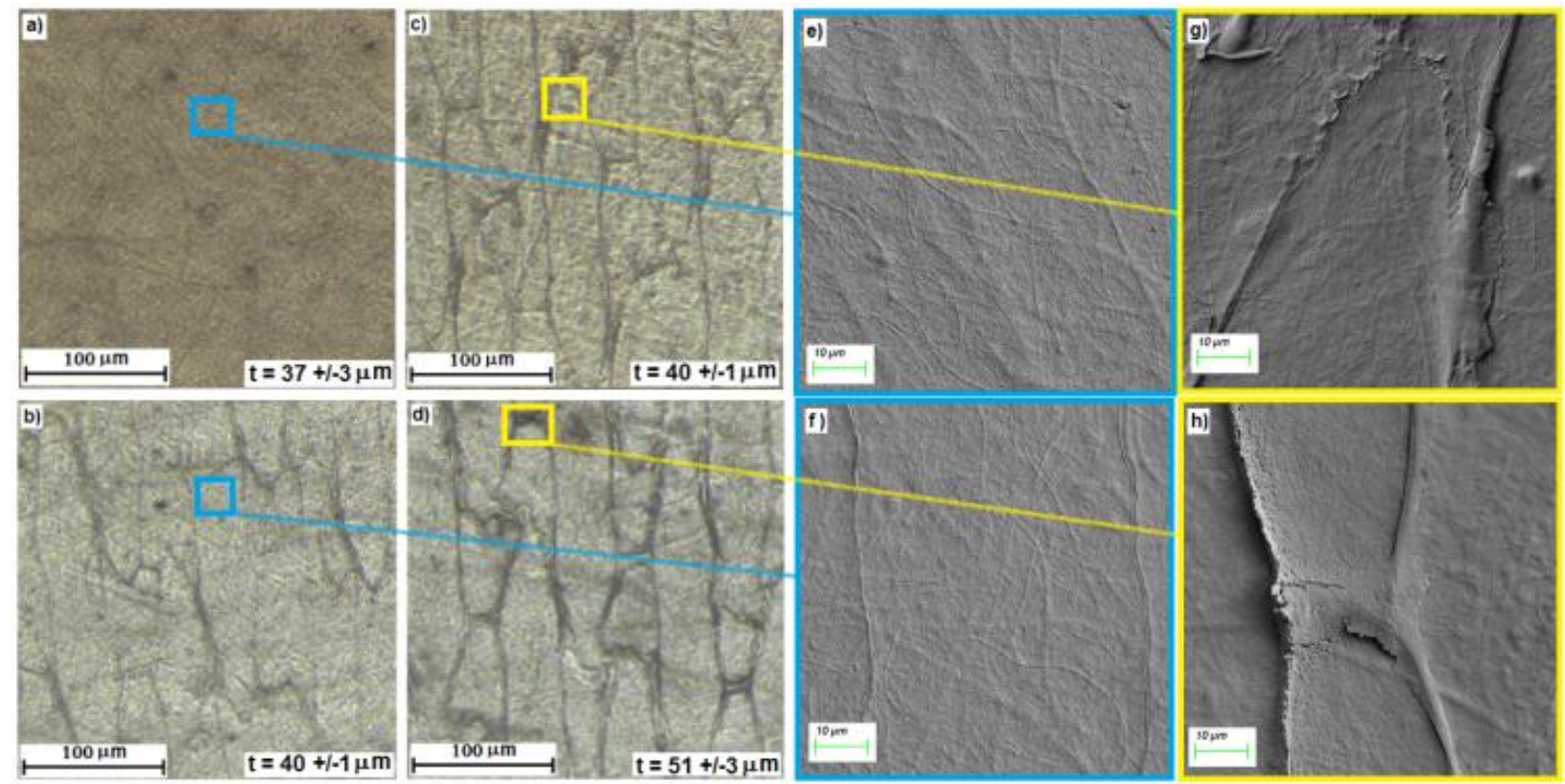

Figure 5. Optical microscopy of CNFF of a) untreated samples and those after treatment with the following ILs: b) $[\mathrm{DBNH}][\mathrm{OAc}]$, c) $[\mathrm{DBNH}][\mathrm{CO} 2 \mathrm{Et}]$, d) [emim][OAc]. Included are also the respective SEM images: e) untreated CNFF samples and those after welding with f) $[\mathrm{DBNH}][\mathrm{OAc}], \mathrm{g})[\mathrm{DBNH}][\mathrm{CO} 2 \mathrm{Et}]$ and h) $[\mathrm{emim}][\mathrm{OAc}]$

The welded films exhibited a clear patterning on their surfaces after the procedure (washing and drying by hot-pressing). A mesh-like surface structure is formed due to the softening at surface level after the plasticization and the subsequent pressing with SEFAR NITEX ${ }^{\circledR}$ fabric used during the hot activation step. This patterning appears in all the samples, being clearer (more extensive plasticization) for the $[\mathrm{emim}][\mathrm{OAc}]$ (Figures $5 \mathrm{~d}, \mathrm{~h}$ ) than for [DBNH][OAc] samples (Figures $5 \mathrm{~b}, \mathrm{f}$ ). Besides the patterning, the welding procedure affects the thickness of the films. For the [emim][OAc] sample (Figure $5 \mathrm{~d}$ ), the thickness increased to $\sim 38 \%$ concerning the initial CNFF thickness, meanwhile for $[\mathrm{DBNH}]\left[\mathrm{CO}_{2} \mathrm{Et}\right]$ (Figure $5 \mathrm{c}$ ) and $[\mathrm{DBNH}][\mathrm{OAc}]$ (Figure $5 \mathrm{~b}$ ) the increment was only $\sim 8 \%$. This behavior might be due to the increased surface roughness brought 
about the template of SEFAR NITEX® Fabric. These results suggest that the welding procedure was sufficient to partially swell the cellulosic material, at least at the surface, creating a thicker and patterned film that visually looked more transparent (see UV-Vis total transmittance results in Figure 6).
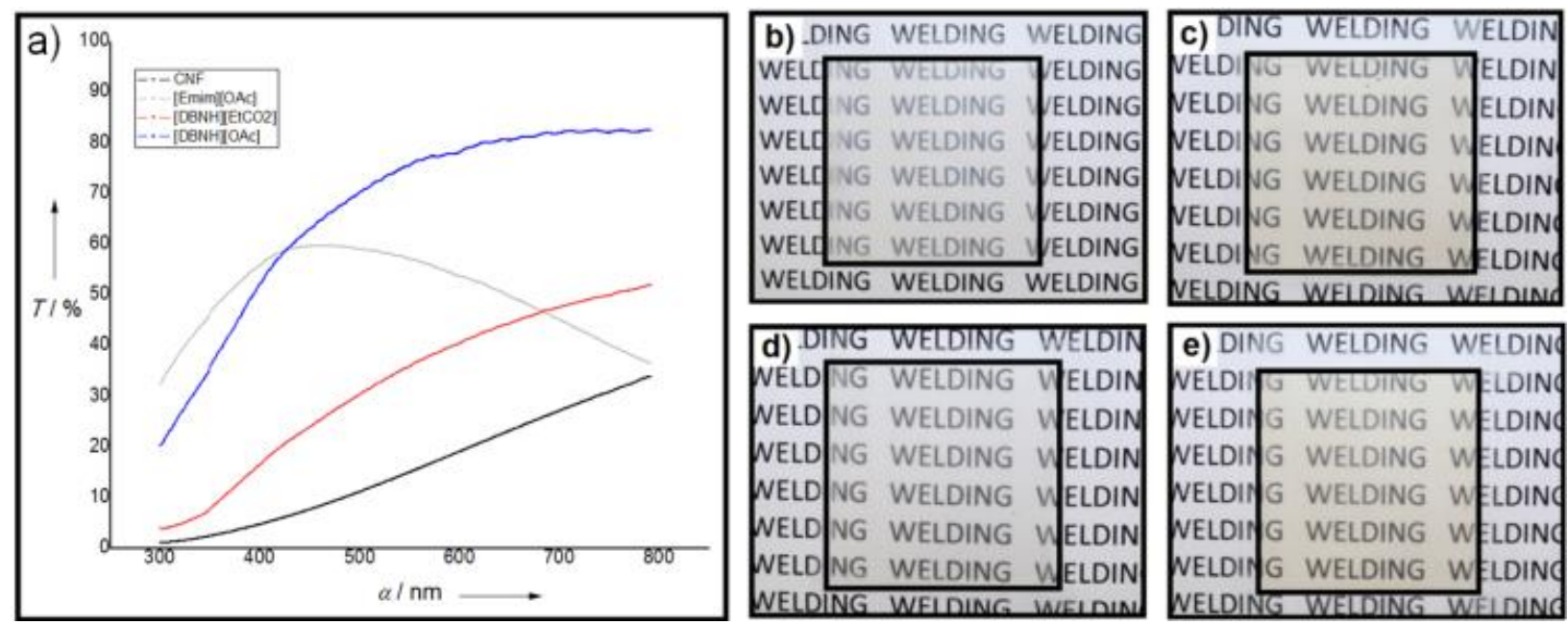

Figure 6. a) UV-Vis transmittance of the welded films: the black profile corresponds to the untreated CNFF, the colored lines correspond to the CNFF welded with the given ILs, as indicated. Images of CNFF films are included for b) untreated sample and those welded with c) $\left.[\mathrm{DBNH}]\left[\mathrm{CO}_{2} \mathrm{Et}\right], \mathrm{d}\right)[\mathrm{emim}][\mathrm{OAc}]$ and e) $[\mathrm{DBNH}][\mathrm{OAc}]$.

In Figure 6, $T$ represents transmittance values and $\alpha$ wavelength; color lines show the respective transmittance values for each IL CNFF treated film.

Despite their larger thickness, the total transmittance data suggest that all welded films resulted in higher transparency (Figure 6b-6e). In the case of the DBN-based ILs, a slight yellowing occurred (see Figure 6c, 6e), which should reduce the total transmittance according to the Rayleigh formalism for scattering in non-absorbing materials, assuming that all samples have the same refractive index ${ }^{60,61}$. This increased transparency is likely due to the surface swelling. IL 
[emim] $[\mathrm{OAc}]$ is best for the dissolution of cellulosic materials ${ }^{29,62}$ and produced more transparent films (Figure 6d), therefore the significant transparency might be the result of mobilization of the cellulose nanofibers and plasticization at the surface level, reducing the light scattering on the surface and increasing the band gap of the film. It is possible to evaluate the visible-shielding ratio (VR) and the UV-blocking ratio (UVR) as the absolute difference between the transmittance of welded films and untreated films, at the wavelengths of $300 \mathrm{~nm}$ and $550 \mathrm{~nm}$ respectively ${ }^{63}$. Table 1, summarizes the VR and UVR results.

Table 1. Visible-shielding ratio (VR) and the UV-blocking ratio (UVR) for the welded films

\begin{tabular}{lll}
\hline IL & $\begin{array}{l}\text { VR } \\
(\%)\end{array}$ & $\begin{array}{l}\text { UVR } \\
(\%)\end{array}$ \\
\hline$[$ emim][OAc] & 2531 & 275 \\
{$[\mathrm{DBNH}]\left[\mathrm{CO}_{2} \mathrm{Et}\right]$} & 231 & 137 \\
{$[\mathrm{DBNH}][\mathrm{OAc}]$} & 1549 & 1028 \\
\hline
\end{tabular}

Since the transmittance of untreated CNFF is lower than that of all the welded films, VR and UVR values in Table 1, represent the relative increase (\%) in transmittance at the respective wavelength, compared with the untreated CNFF as a reference. From Table 1 and Figure 6 it is apparent that $[\mathrm{emim}][\mathrm{OAc}]$ and $[\mathrm{DBNH}][\mathrm{OAc}]$ increased more extensively the transmittance of welded films, suggesting that the acetate ILs are more effective at increasing the transparency. [emim][OAc]-treated films reach a maximum value of around $450 \mathrm{~nm}$, after this, the transmittance decays, reaching similar value to that of the untreated CNFF at $800 \mathrm{~nm}$. This observation might be explained by the stronger effect that this IL has on the CNFF surface, producing better-defined 
patterns (see Figure 5d) that might have an effect on the transmittance of the material at high wavelengths. Also, the formation and retention of chromophores during pressing, in the case of [emim][OAc], is another possible explanation. Changes in surface morphology can also affect other properties, such as wettability, to examine this, water contact angles were measured (Figure 7).

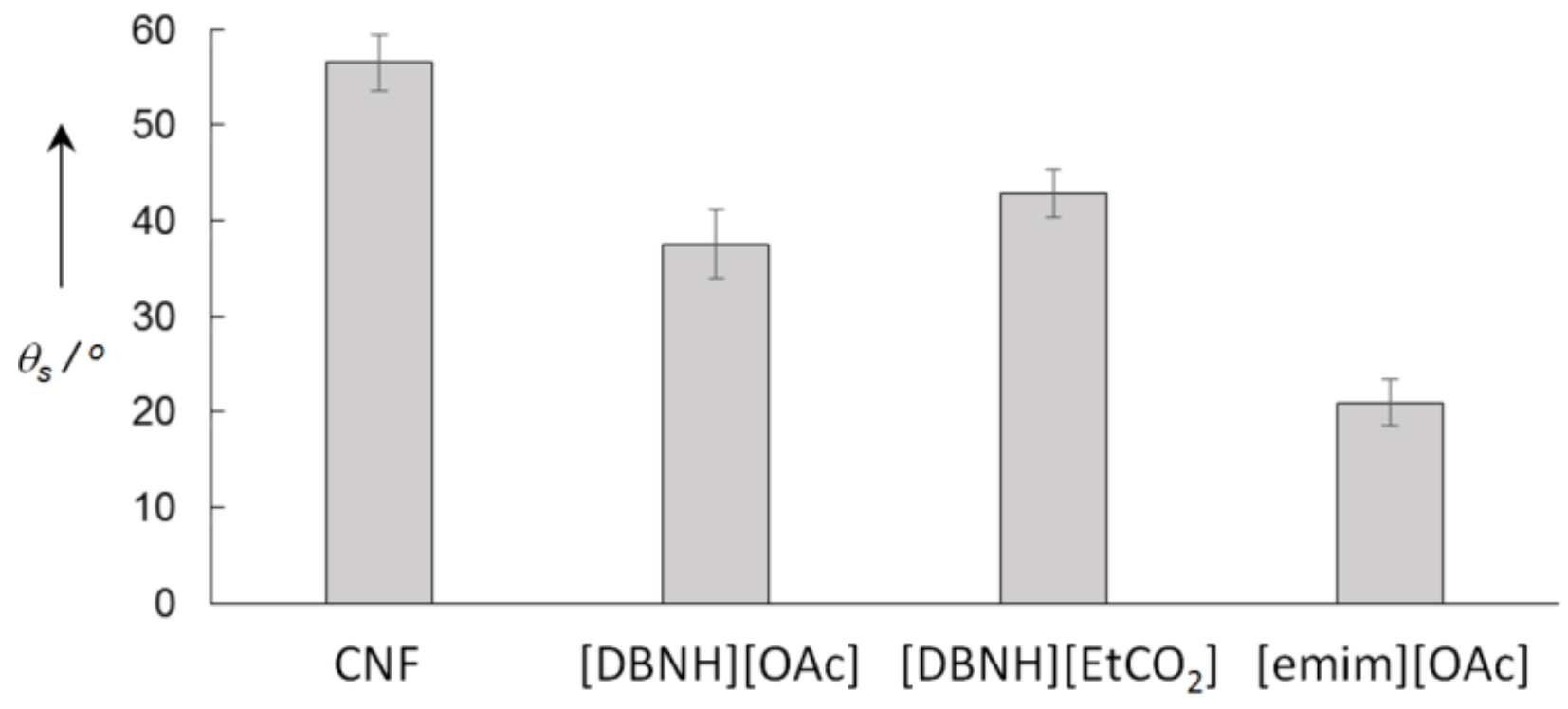

Figure 7. Static water contact angle (WCA, $\theta_{\mathrm{s}}$ ) for films welded with ionic liquids. Sample marked as CNFF corresponds to the reference, unwelded sample

Figure 7 reveals that all samples present lower WCA $\theta_{\mathrm{s}}$ than that for untreated CNFF reported in the literature ${ }^{11}$ and our reference (CNFF in Figure 7). The welded films exhibiting higher transparency have a lower WCA, a phenomenon that is related to the plasticization of cellulose on the film surfaces allowing for morphology changes. The change in WCA may also be related to changes in the film composition, e.g., with additives or the presence of residual IL. These aspects are further investigated. 
For the comparison and analysis of the welding procedure using different substrates and IL types, two materials are taken as reference: a) Polyvinyl alcohol (PVA, $10 \% \mathrm{w} / \mathrm{w}$ in water), which has been used widely as a reinforcement polymer and additive for improvement of mechanical and barrier properties of cellulose film materials ${ }^{64-66}$, b) Filter paper (VWR ${ }^{\circledR}$ particle retention 12-15 $\mu \mathrm{m})$ was used to determine the effect on macrofibers during the welding procedure. The morphology of the welded CNFFs and filter papers were followed through SEM (Figure 8).
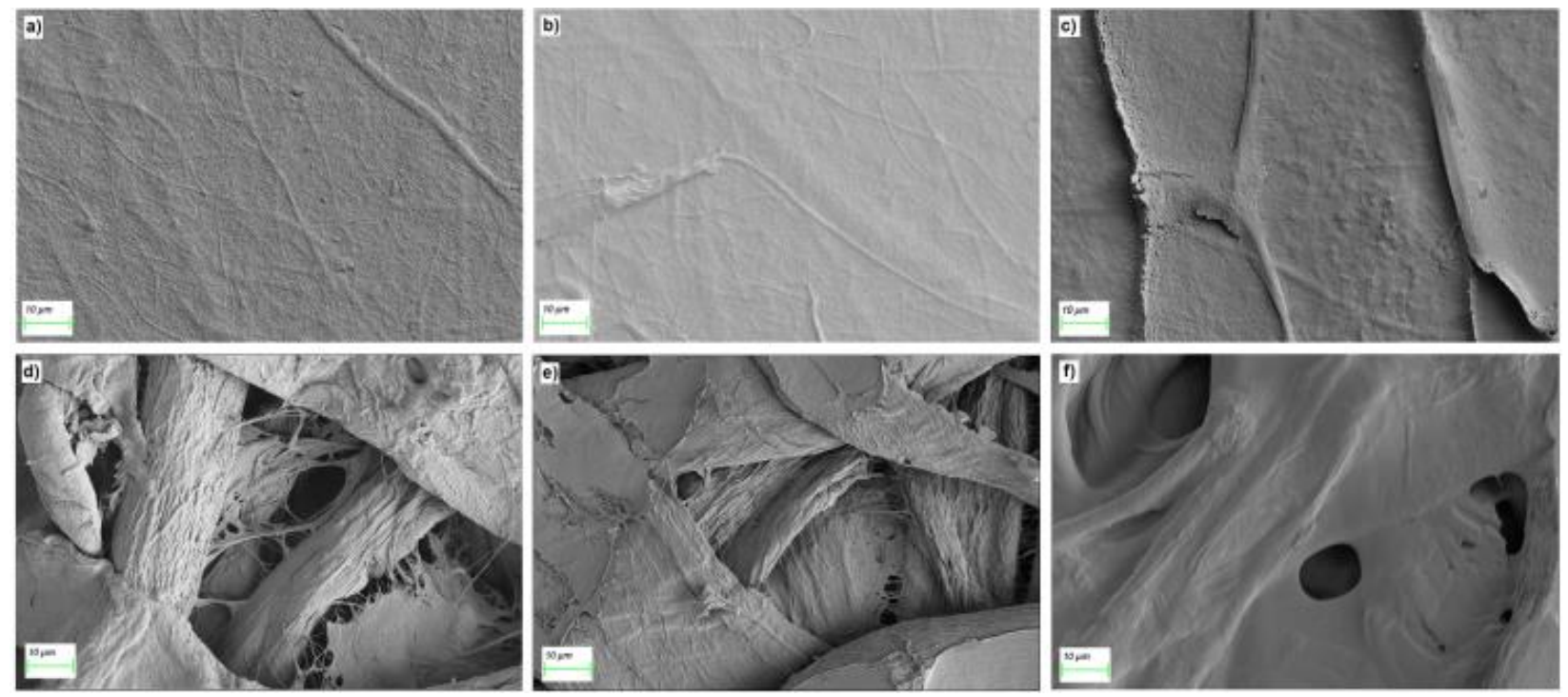

Figure 8. SEM images on $10 \mu \mathrm{m}$ scale for a) untreated CNFF, b) PVA-welded CNFF, c) [emim][OAc]-welded CNFF, d) untreated filter paper, e) PVA-welded filter paper, f) [emim][OAc]-welded filter paper.

As shown in Figure 8, the welding fluid (PVA or IL) and fiber size affects the CNFF morphology (Figure 8a-8c) and filter paper fibers (Figure 8d-8f) after modification. For the untreated CNFF (Figure 8a) and PVA-welded CNFF (Figure 8b), the images are similar, showing unaffected nanocellulose fibers several micrometers long. However, the PVA-welded CNFF shows slightly 
less textured material, consistent with the filling of voids between fibrils with polymer and no extrusion of the fibrils between the filter pores. When the welding procedure involves [emim][OAc] (Figure 8c), it is possible to observe complete plasticization on the film surface and related patterning of the surface, during the hot activation step using the porous SEFAR NITEX ${ }^{\circledR}$ fabric. The patterning on the CNF surface is due to softening of cellulose fiber on top of the film during the welding procedure. These fibers then extrude into the pores of the filter. This extrusion also adds extra thickness to the film, (see Figure 5). When the welding procedure is carried out on the filter paper (Figures 8d-8f) it is possible to observe a similar texturing of the surface, with the difference that film thickening does not occur. Since the fibers in the filter paper are larger, with much more complex morphology and entanglement than the mechanically-fibrillated fibrils, the surface softening decreases the void spaces on the surface, but extrusion of the fibres into the filter pores is prevented (Figure 8f). The welding reduces the thickness from $214 \pm 11 \mu \mathrm{m}$ (Figure $8 \mathrm{~d}$ ) to $140 \pm 8 \mu \mathrm{m}$, and $116 \pm 4 \mu \mathrm{m}$ for the PVA (Figure 8e) and [emim][OAc] (Figure 8f) welded film, respectively. In these cases, the IL yielded a more compact surface for macrofibers (filter paper) and patterned surfaces for nanofibers (CNF), see Figure 9. 

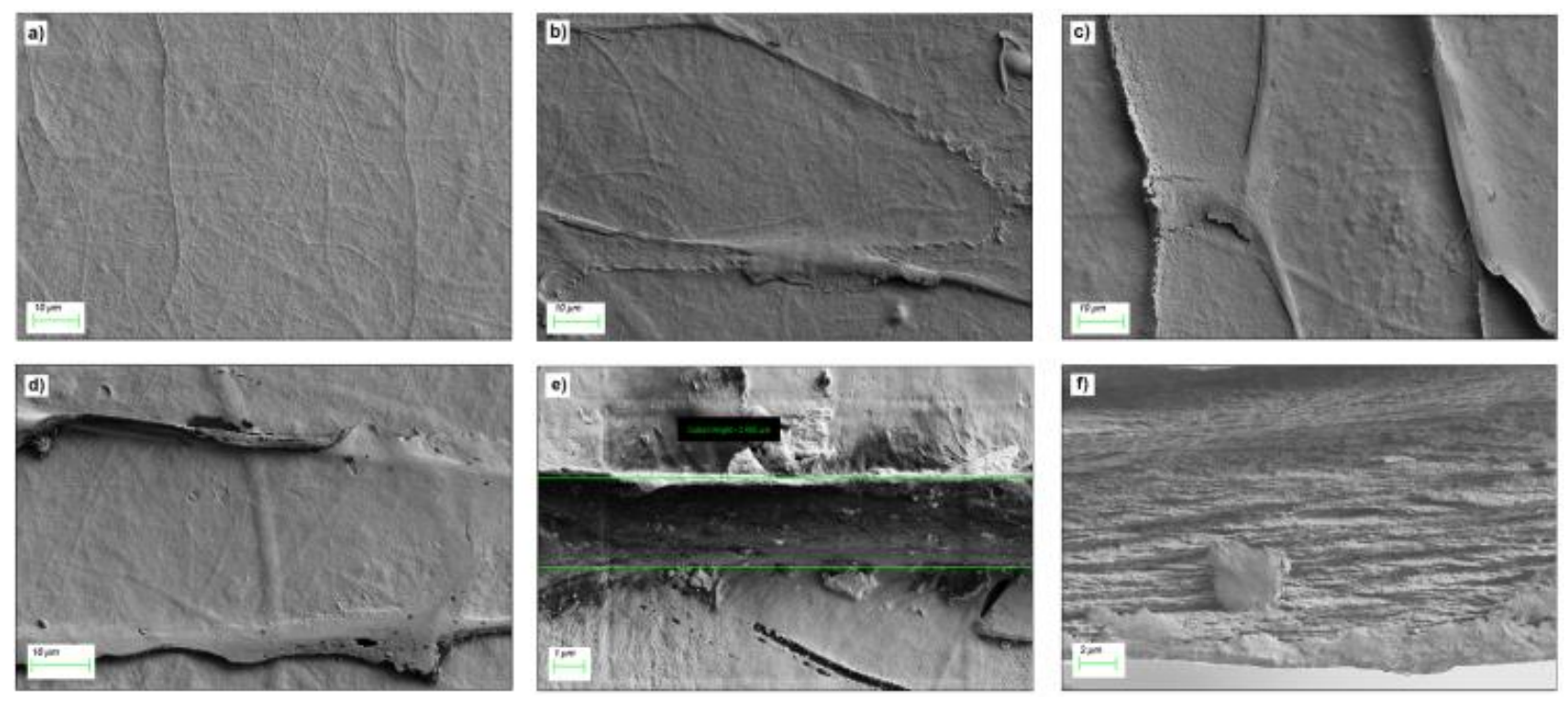

Figure 9. SEM images of patterns from the surface for IL-welded CNFFs after treatment with a) $\left.\left.\left.[\mathrm{DBNH}][\mathrm{OAc}], \mathrm{b})[\mathrm{DBNH}]\left[\mathrm{CO}_{2} \mathrm{Et}\right], \mathrm{c}\right)[\mathrm{emim}][\mathrm{OAc}], \mathrm{d}\right)[\mathrm{emim}][\mathrm{OAc}], \mathrm{e}\right)[\mathrm{emim}][\mathrm{OAc}]($ height of the pattern created on the surface). Figure f) shows the welded film (with [emim][OAc]), cross section after liquid nitrogen fracture.

The [emim][OAc]-welded CNFF markedly exhibits the patterning effect (Figure 9c) while the $[\mathrm{DBNH}][\mathrm{OAc}]-$ welded CNFF exhibits the least effect. The [DBNH][OAc] welding procedure affords a thin line on the CNFF surface ( $1 \mu \mathrm{m}$ diameter) (Figure $9 \mathrm{a})$. Whereas, for the $[\mathrm{DBNH}]\left[\mathrm{CO}_{2} \mathrm{Et}\right]$ a slightly larger pattern was observed $(1.7 \pm 0.5 \mu \mathrm{m}$ diameter $)$. The most evident pattern was exhibited after $[\mathrm{emim}][\mathrm{OAc}]$ treatment (Figures 9c-9f), with the most significant pattern $(3.8 \pm 0.7 \mu \mathrm{m}$ diameter $)$. Thus, it is possible to conclude that [emim][OAc] is most effective at surface patterning, presumably related to its excellent ability at dissolving cellulose.

The CNFF plasticization results are in good agreement with the experimental results for cellulose dissolution with the corresponding ILs. Experimentally, acetate containing ILs have shown more rapid and effective cellulose dissolution compared to propionate containing ILs ${ }^{29}$; therefore, the 
ILs [DBNH][OAc], [emim] [OAc], are expected to be the best at dissolving cellulose. This last was true only for the films treated with [emim][OAc] (Figure 9c-f), the patterning obtained for the samples treated with the IL [DBNH][OAc] (Figure 9a) were not that effective, in this case, the homologous [DBNH] $\left[\mathrm{CO}_{2} \mathrm{Et}\right]$ (Figure 9b) exhibit a broader and more effective plasticization, this can be explained since $[\mathrm{DBNH}][\mathrm{OAc}]$ is not a room temperature $\mathrm{IL}\left(\mathrm{mp} 63{ }^{\circ} \mathrm{C}\right){ }^{33}$, and it was mixed with $5 \% \mathrm{w} / \mathrm{w}$ of gamma-valerolactone $(\mathrm{GVL})$ an effective reported co-solvent for biomass dissolution ${ }^{67,68}$. The welding dipping procedure was performed with the mixture at room temperature. In this case, the immersion temperature of CNFF into the IL seems to play an essential role in the plasticization process. On the other hand, as mentioned previously, the cation plays a synergistic effect on cellulose dissolution. When the side chain length of alkyl groups or the symmetry of cations increased, the dissolution rate of cellulose in ILs decreased, because of the increase of viscosity and the decrease of $\mathrm{H}$-bond acidity ${ }^{27,33}$, this explains why the [emim][OAc] IL is more effective at dissolving and plasticizing cellulose surface than [DBNH][OAc], due to the less symmetric and bulkier [DBNH] cation. In conclusion, an effective IL for dissolving cellulose should have suitable cationic and anionic structures, to interact with cellulose actively and make it more favorable to dissolve in the $\mathrm{IL}^{27,30,32}$.

Mechanical and barrier properties. Nanocellulose films are formed by the collapse of fibers dissolved in aqueous media. Thus, highly packed structures are formed with high mechanical performance, theoretically with a similar mechanical performance to steel ${ }^{69}$. All the samples showed a fracture of the fragile type, with an almost perfect horizontal fracture line.

Optical and SEM images (Figures 4, 5, 8, 9) of welded films suggested that surface texturing of welded films occurs, which may also affect their mechanical properties. Therefore, strength and 
barrier properties were measured. Stress-strain curves for CNFF (IL welded and untreated) are shown in Figure 10.

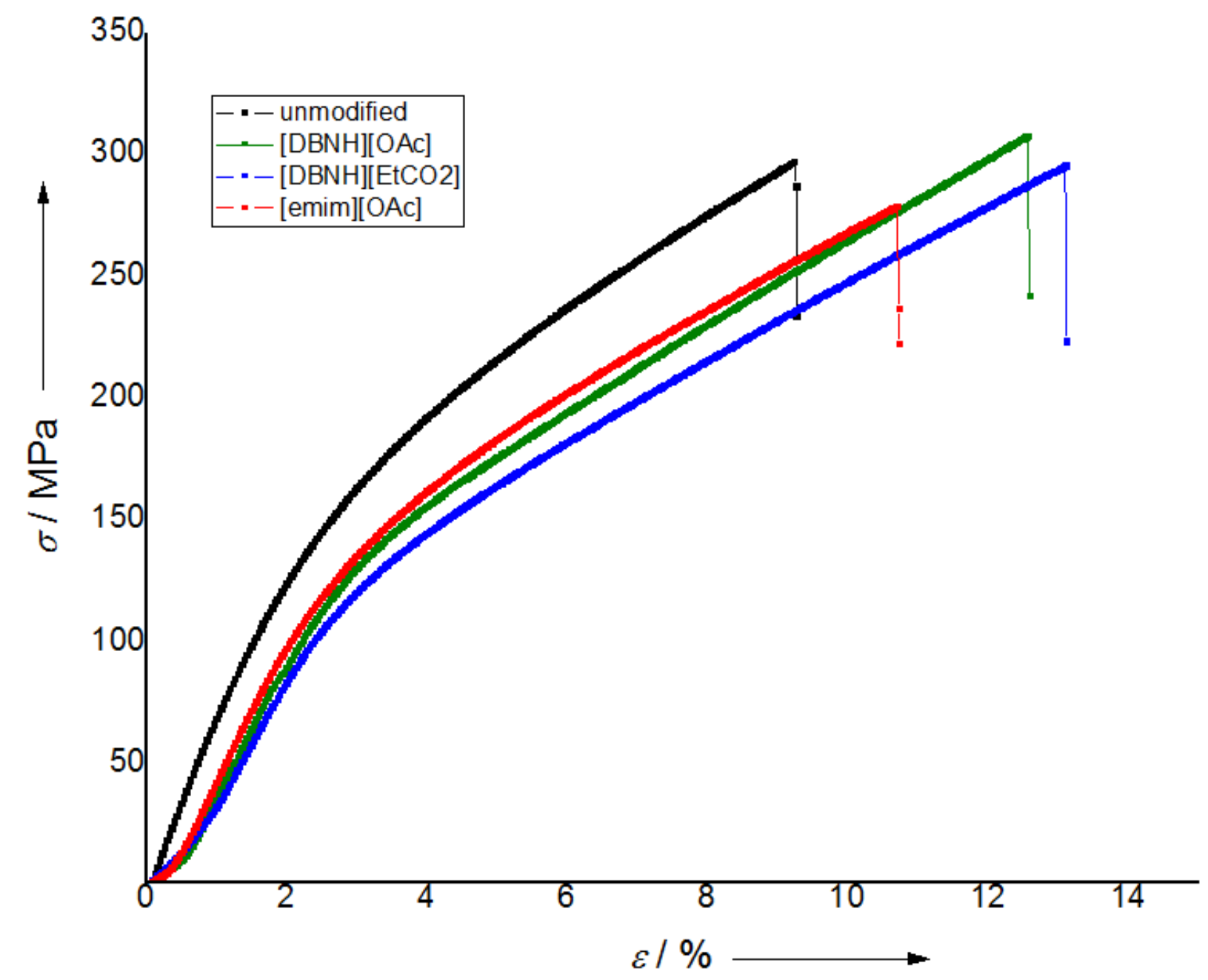

Figure 10. Stress-strain tensile curves for welding CNFF with the respective ILs: untreated (black), [DBNH][OAc] (green), [DBNH][$\left[\mathrm{CO}_{2} \mathrm{Et}\right]$ (blue), [emim][OAc] (red).

In Figure 10, $\sigma$ represents the tensile stress and $\varepsilon$ the tensile strain. The mechanical properties of the different samples are summarized in Table 2. The CNFFs present excellent mechanical properties, compared to those reported in the literature for similar films. For example, Qing ${ }^{14}$ 
reported films with a maximum Young's modulus of $4.84 \pm 0.12 \mathrm{GPa}$, corresponding to a formulation of CNF with $15 \%$ of phenol formaldehyde resin. In our study, the CNFFs reached values of $7.2 \pm 0.1 \mathrm{GPa}$ for the unmodified films, and in the worst case, for the IL welded films, this value drops to $5.8 \pm 0.1 \mathrm{GPa}$. Similar behavior is observed by comparing stress at break, where the maximum value reported by Qing was $232 \pm 22 \mathrm{MPa}$ compared to $294 \pm 13 \mathrm{MPa}$ and a minimum of $265 \pm 13 \mathrm{MPa}$, obtained in the present study. In another study by Yano ${ }^{70}$ an improved value over CNF films for the modulus is reported by the addition of $2 \%$ of oxidized starch. However, in the present study, improvement in the toughness of the CNFFs after the IL welding procedure is also observed (Figure 11 and Table 2).

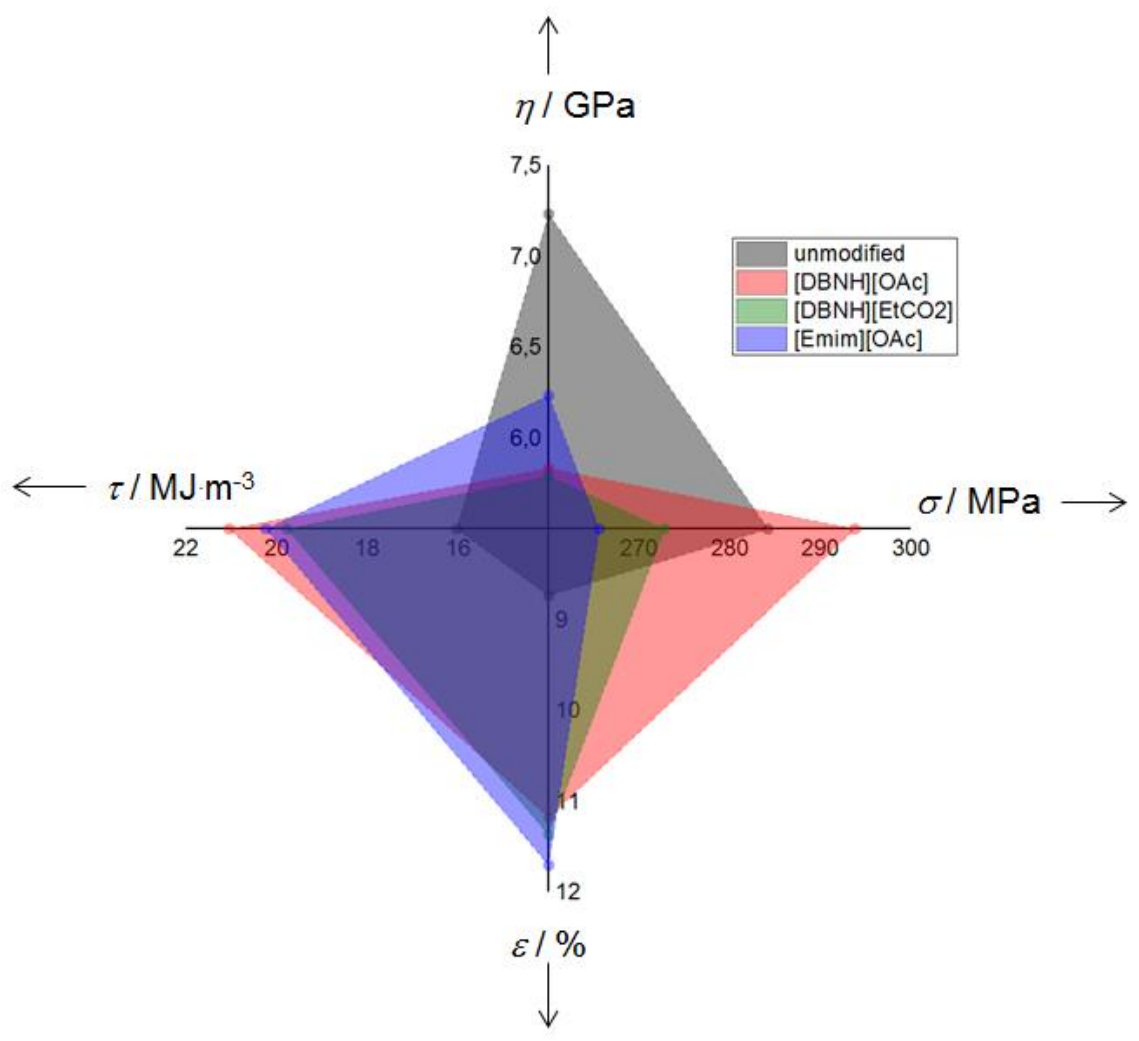

Figure 11. Mechanical properties of CNFF welded with the corresponding IL. 
In Figure 11, $\eta$ represents the young modulus, $\sigma$ the tensile stress at yield, $\tau$ the toughness and $\varepsilon$ the tensile strain at yield. Figure 11 compares Young's modulus, tensile stress at yield, toughness and tensile strain at yield for all the samples studied. It is clear that the toughness increases in all the welded samples, from $24 \%$ to $31 \%$, concerning the untreated CNFF. Nevertheless, not all the mechanical properties have improved. The toughness increases mainly because of the higher tensile strain, even though the modulus decreases between $14 \%$ to $20 \%$ for the welded films.

Table 2. Mechanical properties of CNFF welded with different ILs

\begin{tabular}{lllll}
\hline Properties & $\begin{array}{l}\text { Unmodified } \\
\text { CNFF }\end{array}$ & $\begin{array}{l}{[\mathrm{DBNH}]} \\
{[\mathrm{OAc}]} \\
\mathrm{CNFF}\end{array}$ & $\begin{array}{l}{[\mathrm{DBNH}]} \\
{\left[\mathrm{CO}_{2} \mathrm{Et}\right]}\end{array}$ & $\begin{array}{l}{[\mathrm{emim}]} \\
{[\mathrm{OAc}]}\end{array}$ \\
\hline $\begin{array}{l}\text { Modulus } \\
\text { [GPa] }\end{array}$ & $7.2 \pm 0.1$ & $5.8 \pm 0.8$ & $5.8 \pm 0.8$ & $6.2 \pm 0.6$ \\
$\begin{array}{l}\text { Tensile stress } \\
\text { at yield [MPa] }\end{array}$ & $284 \pm 27$ & $294 \pm 13$ & $273 \pm 17$ & $265 \pm 13$ \\
$\begin{array}{l}\text { Tensile Strain } \\
\text { at Yield [\%] }\end{array}$ & $8.7 \pm 1.1$ & $11.2 \pm 1$ & $11.4 \pm 1.2$ & $11.7 \pm 1.4$ \\
$\begin{array}{l}\text { Toughness } \\
\text { [MJ.m }{ }^{-3} \text { ] }\end{array}$ & $16 \pm 3.0$ & $21 \pm 1.7$ & $19.8 \pm 2.7$ & $20 \pm 3$ \\
\hline
\end{tabular}

From Figure 11 and Table 2 it is possible to see that the IL welding treatment improves the toughness, particularly for the [DBNH][OAc] welded CNFF, to produce higher tensile stress at yield $294 \pm 13 \mathrm{MPa}$ and higher toughness $21 \pm 1.7 \mathrm{MJ}^{-3}$. Meanwhile, the [emim][OAc] welded CNFF produces a more flexible film, reaching a tensile strain at yield of $11.7 \pm 1.4 \%$. In general the welded films exhibit higher average tensile strains compared to the respective value for the untreated films; meanwhile, the other mechanical properties remained almost constant. The 
increased percentage in the average tensile strain $(29 \%, 31 \%$ and $34 \%$ for [DBNH] [OAc], [DBNH] $\left[\mathrm{CO}_{2} \mathrm{Et}\right]$, [emim] [OAc] ILs respectively) was enough to increase the average toughness $\left(31 \%, 24 \%, 25 \%\right.$ for $[\mathrm{DBNH}][\mathrm{OAc}],[\mathrm{DBNH}]\left[\mathrm{CO}_{2} \mathrm{Et}\right]$, [emim] [OAc] ILs respectively) with respect to untreated samples. The standard deviations could be minimized in future works, considering a more extensive and optimized welding procedure.

In addition to the strength of the films, another expectation of nanocellulose-based films is the possibility to work as a barrier for gas and liquids, in the context of packaging ${ }^{7}$. Thus, OTR and WVTR were measured, Figure 12 shows the results.

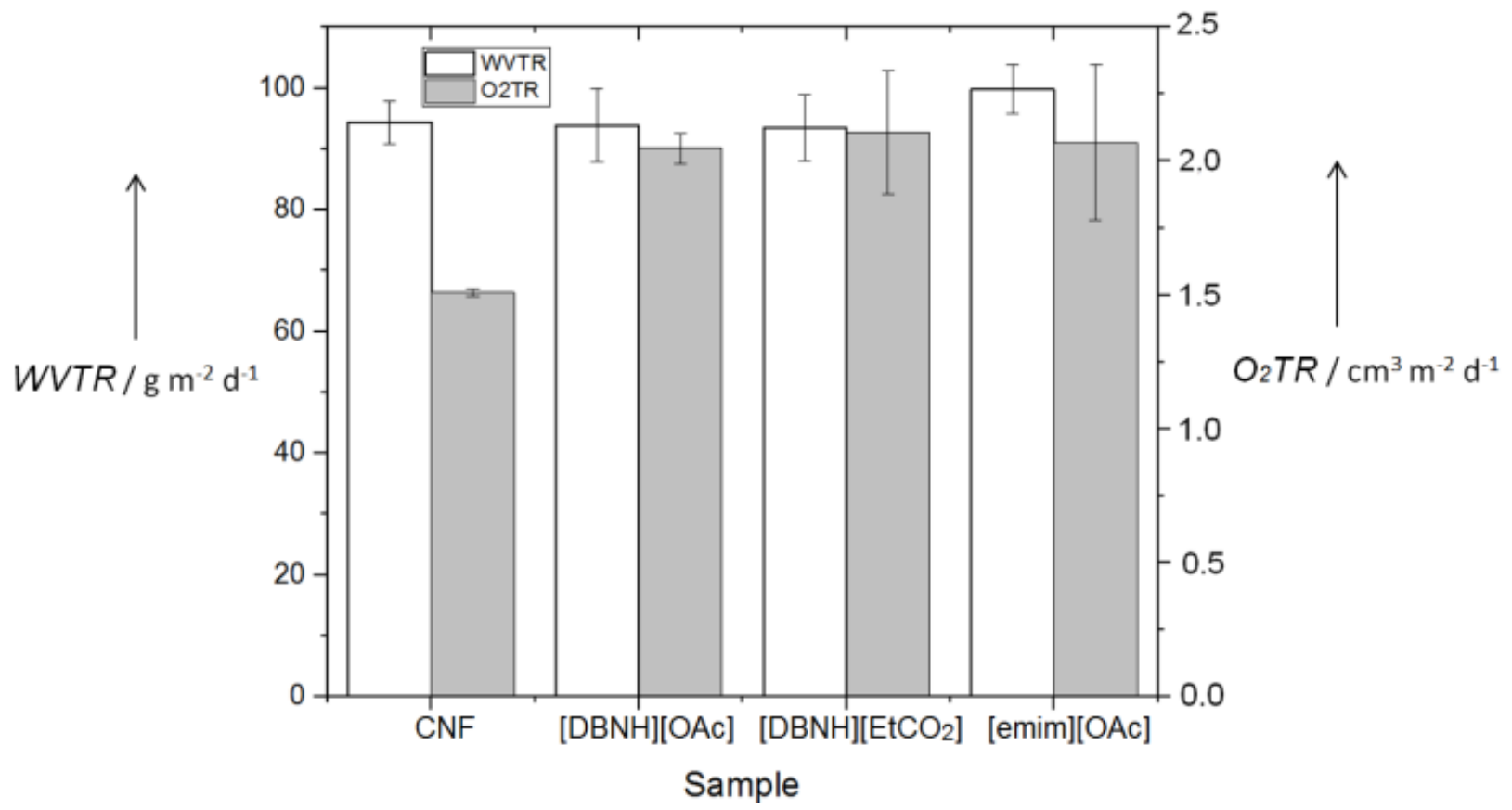

Figure 12. Barrier properties of CNFF welded with the corresponding ILs.

The oxygen and water barrier properties of the unmodified CNFF agrees well with reported values for neat $\mathrm{CNFF}^{6,7,13,14,16,69,70}$. From Figure 12 it is clear that the WVTR for the welded films remains almost the same for all the samples, except the [emim][OAc]-welded films that show a 
small increase, about 5.7\%, compared to untreated CNFF. The OTR increased in all treated samples by around $27 \%$. This result confirms that the welding process in its current implementation does not improve the barrier properties, the exact reasons for which are uncertain. On the other hand, the welding process might be promising for improving the transport properties on macrofiber systems where there is more porosity (Figure $8 \mathrm{f}$ ), this will be the subject of further work.

On the mechanism of welding. Much evidence has been given showing that the fibers have been softened or plasticized to such an extent that they can be extruded into the filter pores and the properties of the films modified to varying degrees. However, the degree of swelling of the bulk film is not apparent from the previous measurements. As these types of ILs are known to dissolve cellulose, a suitable method for determining the degree of swelling or even dissolution is XRD, which monitors changes in crystallinity after removal of the ILs (Figure 13) 


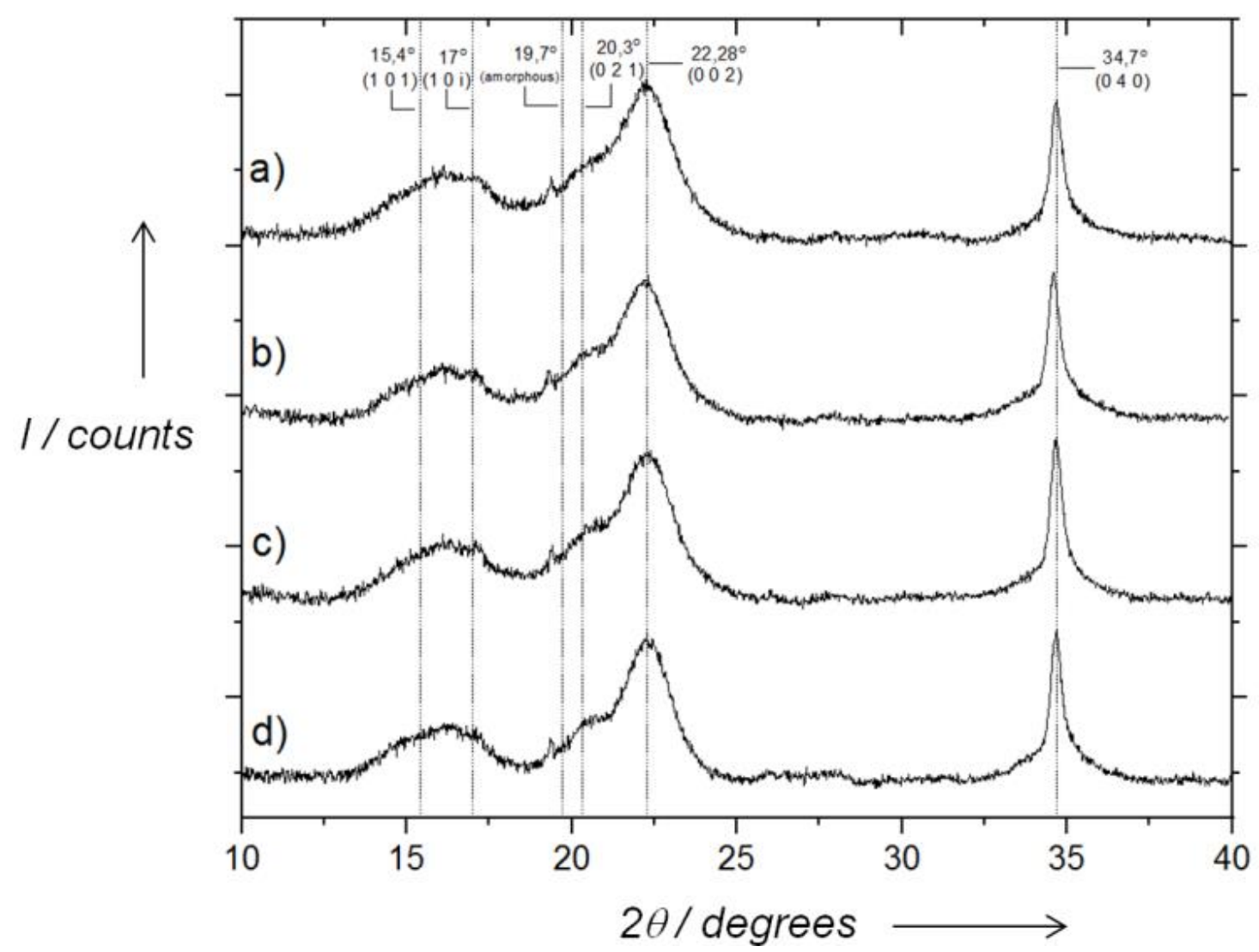

Figure 13. XRD diffractograms for the CNFFs: a) untreated, b) [emim][OAc] welded, c) $[\mathrm{DBNH}]\left[\mathrm{CO}_{2} \mathrm{Et}\right]$ welded, d) $[\mathrm{DBNH}][\mathrm{OAc}]$ welded.

Diffraction patterns for all samples (Figure 13) shows a clear fingerprint of cellulose allomorph type I ${ }^{43,44}$. All samples are compared with the untreated CNFF (Figure 13a). No significant changes in crystallinity are observed after the welding procedure indicating that only a minor fraction of the cellulose was solvated during the welding procedure. Otherwise, a more substantial contribution of amorphous or cellulose II would be expected, therefore, what is happening at the surface level is the fiber plasticization due to mobility caused by IL impregnation, this is consistent with surface plasticization during the welding, allowing for extrusion surface cellulose into the filter. Some orientation of the nanofibrils is evident, from the prominence of the $\left(\begin{array}{lll}0 & 4\end{array}\right)$ peak at 
34. $7^{\circ}$. The $\left(\begin{array}{lll}0 & 4 & 0\end{array}\right)$ peak is the sum of different contributions located from $33^{\circ}$ until $35^{\circ}{ }^{37}$, additionally this peak increases when the XRD pattern is taken on transmission mode ${ }^{44}$. In general, the data shown in Figure 13 agrees well with the typical cellulose I polymorph.

The deconvolution method was used for decomposing the data to its different peaks contributions ${ }^{37,71}$. Figure Sa3 (see the supporting information) shows the deconvolution of XRD pattern for CNF untreated films. The CNFF sample studied in Figure 13, and Figure Sa3 agrees well with the pattern and deconvoluted Gaussian curves reported in the literature ${ }^{43}$. CNFF in this work presented a wide amorphous peak around $19,7^{\circ}$, giving a crystallinity index value of $62 \pm 0.5$ $\%$. Additionally, crystallite sizes for the $\left(\begin{array}{lll}0 & 0 & 2\end{array}\right)$ and $\left(\begin{array}{lll}0 & 4 & 0\end{array}\right)$ diffraction planes were calculated, see Table Sa3 (see the supporting information). The values are consistent with those reported in the literature ${ }^{43}$. From Table $\mathrm{Sa} 3$ it is possible to notice that there is no change in crystallite sizes after welding with IL.

\section{CONCLUSIONS}

Welding was performed on Cellulose Nanofiber Films (CNFF) by using Ionic Liquids (ILs): 1ethyl-3-methylimidazolium acetate [emim][OAc], 1,5-Diazabicyclo[4.3.0]non-5-enium propionate $[\mathrm{DBNH}]\left[\mathrm{CO}_{2} \mathrm{Et}\right]$, 1,5-Diazabicyclo[4.3.0]non-5-enium acetate [DBNH][OAc]. The CNFF obtained exhibited interesting physical properties, including surface patterning, transparency, and increased toughness (in the range of $24-31 \%$ concerning the untreated CNFF). The results are explained by the partial dissolution ability of the ionic liquids at the films surfaces level. It is clear that the IL that better dissolves cellulose [emim][OAc], shows a higher effect for some properties such as transparency and tensile strain (increasing the toughness) but also produces a more depth in the patterning of the surface. This fact offsets the partial dissolution 
effect, for example, the transparency decreased monotonically at wavelengths above $420 \mathrm{~nm}$ for the films treated with $[\mathrm{emim}][\mathrm{OAc}]$. The IL derived from the $[\mathrm{DBNH}]$ cation, with lower ability to dissolve cellulose, exhibited a more promising effect, for example, [DBNH][OAc] produced films with higher tensile stress at yield $294 \pm 13 \mathrm{MPa}$ and higher toughness $21 \pm 1.7 \mathrm{MJ}^{-3}$; meanwhile, the IL [emim] [OAc] produced the more flexible films, with a tensile strain at yield of $11.7 \pm 1.4 \%$. In spite these mechanical properties and complete removal of ILs after treatment (confirmed by liquid NMR), the welding process needs some substantial modifications to be used on barrier films synthesis, even though the aspects studied here contributes to the development of greener alternatives to synthetic polymers in related applications.

\section{ASSOCIATED CONTENT}

\section{Supporting Information.}

Reagents and solvents, diffractometer angles references for cellulose I and II polymorphs with XRD scattering of CNFF treated samples crystallite sizes for the $\left(\begin{array}{lll}0 & 0\end{array}\right)$ and $\left(\begin{array}{lll}0 & 4\end{array}\right)$ diffraction planes, atomic force microscopy of fibers after microfluidization and films synthesis equipment (Supporting_Information_AppendixA.PDF).

NMR assignments for cellulose (AGU) and xylan (AXU) resonances for BKP CNFF dissolved in [P4444][OAc]:DMSO-d6, HSQC and TOCSY NMR analysis of the untreated CNFFs dissolved in [P4444][OAc]:DMSO-d6 (Supporting_Information_AppendixB.PDF) 


\section{AUTHOR INFORMATION}

\section{Corresponding Author}

*E-mail: greyes@ubiobio.cl

\section{Author Contributions}

The manuscript was written through the contributions of all authors. All authors have given the approval to the final version of the manuscript.,,$++ \S$ these authors contributed equally.

\section{ACKNOWLEDGMENT}

G.R. Acknowledges the contribution of Becas Chile for supporting the postdoctoral studies at Aalto University. We acknowledge the provision of facilities and technical support by Aalto University at OtaNano - Nanomicroscopy Center (Aalto-NMC). The authors would also like to acknowledge the Academy of Finland for funding under the project 'WTF-Click-Nano' (311255).

\section{REFERENCES}

(1) Lilja, K. Wood-Based. Bioeconomy Solving Global Challenges; Lilja, K., Aalto University, Loukola-Ruskeeniemi, K., Ministry of Economic Affairs and Employment of Finland, Eds.; Ministry of Economic Affairs and Employment of Finland: Helsinki, 2017.

(2) Foster, E. J.; Moon, R. J.; Agarwal, U. P.; Bortner, M. J.; Bras, J.; Camarero-Espinosa, S.; Chan, K. J.; Clift, M. J. D.; Cranston, E. D.; Eichhorn, S. J.; Fox, D. M.; Hamad, W. Y.; Heux, L.; Jean, B.; Korey, M.; Nieh, W.; Ong, K. J.; Reid, M. S.; Renneckar, S.; Roberts, R.; Shatkin, J. A.; Simonsen, J.; Stinson-Bagby, K.; Wanasekara, N.; Youngblood, J. 
Current Characterization Methods for Cellulose Nanomaterials. Chem. Soc. Rev. 2018, 47, 2609-2679.

(3) Habibi, Y.; Lucia, L. A.; Rojas, O. J. Cellulose Nanocrystals: Chemistry, Self-Assembly, and Applications. Chem. Rev. 2010, 110, 3479-3500.

(4) Schütz, C.; Sort, J.; Bacsik, Z.; Oliynyk, V.; Pellicer, E.; Fall, A.; Wågberg, L.; Berglund, L.; Bergström, L.; Salazar-Alvarez, G. Hard and Transparent Films Formed by Nanocellulose-TiO2 Nanoparticle Hybrids. PLoS One 2012, 7, 1-8.

(5) Herrera Rodriguez, M. Preparation and Characterization of Nanocellulose Films and Coatings from Industrial Bio-Residues; 2015.

(6) Azeredo, H. M. C.; Mattoso, L. H. C.; Avena-Bustillos, R. J.; Filho, G. C.; Munford, M. L.; Wood, D.; McHugh, T. H. Nanocellulose Reinforced Chitosan Composite Films as Affected by Nanofiller Loading and Plasticizer Content. J. Food Sci. 2010, 75, 1-7.

(7) Azeredo, H. M. C. de. Nanocomposites for Food Packaging Applications. Food Res. Int. 2009, 42, 1240-1253.

(8) Voisin, H.; Bergström, L.; Liu, P.; Mathew, A. Nanocellulose-Based Materials for Water Purification. Nanomaterials 2017, 7, 57.

(9) Herrera, M. A.; Mathew, A. P.; Oksman, K. Barrier and Mechanical Properties of Plasticized and Cross-Linked Nanocellulose Coatings for Paper Packaging Applications. Cellulose 2017, 24, 3969-3980.

(10) Shimizu, M.; Saito, T.; Fukuzumi, H.; Isogai, A. Hydrophobic, Ductile, and Transparent Nanocellulose Films with Quaternary Alkylammonium Carboxylates on Nanofibril Surfaces. Biomacromolecules 2014, 15, 4320-4325.

(11) Guo, J.; Filpponen, I.; Johansson, L. S.; Heißler, S.; Li, L.; Levkin, P.; Rojas, O. J. Micro- 
Patterns on Nanocellulose Films and Paper by Photo-Induced Thiol-yne Click Coupling: A Facile Method toward Wetting with Spatial Resolution. Cellulose 2018, 25, 367-375.

(12) Yang, S.; Xie, Q.; Liu, X.; Wu, M.; Wang, S.; Song, X. Acetylation Improves Thermal Stability and Transmittance in FOLED Substrates Based on Nanocellulose Films. RSC Adv. 2018, 8, 3619-3625.

(13) Hubbe, M. A.; Ferrer, A.; Tyagi, P.; Yin, Y.; Salas, C.; Pal, L.; Rojas, O. J. Nanocellulose in Thin Films, Coatings, and Plies for Packaging Applications: A Review. BioResources 2017, 12, 2143-2233.

(14) Qing, Y.; Sabo, R.; Wu, Y.; Cai, Z. High-Performance Cellulose Nanofibril Composite Films. BioResources 2012, 7, 3064-3075.

(15) Sun, X.; Wu, Q.; Zhang, X.; Ren, S.; Lei, T.; Li, W.; Xu, G.; Zhang, Q. Nanocellulose Films with Combined Cellulose Nanofibers and Nanocrystals: Tailored Thermal, Optical and Mechanical Properties. Cellulose 2018, 25, 1103-1115.

(16) Kumar, V.; Bollström, R.; Yang, A.; Chen, Q.; Chen, G.; Salminen, P.; Bousfield, D.; Toivakka, M. Comparison of Nano- and Microfibrillated Cellulose Films. Cellulose 2014, $21,3443-3456$.

(17) Nair, S. S.; Zhu, J.; Deng, Y.; Ragauskas, A. J. High Performance Green Barriers Based on Nanocellulose. Sustain. Chem. Process. 2014, 2, 1-7.

(18) Haverhals, L. M.; Reichert, W. M.; De Long, H. C.; Trulove, P. C. Natural Fiber Welding. Macromol. Mater. Eng. 2010, 295, 425-430.

(19) Haverhals, L. M.; Nevin, L. M.; Foley, M. P.; Brown, E. K.; De Long, H. C.; Trulove, P. C. Fluorescence Monitoring of Ionic Liquid-Facilitated Biopolymer Mobilization and Reorganization. Chem Commun 2012, 48, 6417-6419. 
(20) Haverhals, L. M.; Sulpizio, H. M.; Fayos, Z. A.; Trulove, M. A.; Reichert, W. M.; Foley, M. P.; De Long, H. C.; Trulove, P. C. Process Variables That Control Natural Fiber Welding: Time, Temperature, and Amount of Ionic Liquid. Cellulose 2012, 19, 13-22.

(21) Haverhals, L. M.; Foley, M. P.; Brown, E. K.; Fox, D. M.; De Long, H. C.; Trulove, P. C. Natural Fiber Welding: Ionic Liquid Facilitated Biopolymer Mobilization and Reorganization. In Ionic Liquids: Science and Applications; pp 145-166.

(22) Tisserat, B.; Larson, E.; Gray, D.; Dexter, N.; Meunier, C.; Moore, L.; Haverhals, L. Ionic Liquid-Facilitated Preparation of Lignocellulosic Composites. Int. J. Polym. Sci. 2015, $2015,1-8$

(23) Durkin, D. P.; Ye, T.; Larson, E. G.; Haverhals, L. M.; Livi, K. J. T.; De Long, H. C.; Trulove, P. C.; Fairbrother, D. H.; Shuai, D. Lignocellulose Fiber- and Welded FiberSupports for Palladium-Based Catalytic Hydrogenation: A Natural Fiber Welding Application for Water Treatment. ACS Sustain. Chem. Eng. 2016, 4, 5511-5522.

(24) Mashkour, M.; Tajvidi, M.; Kimura, F.; Yousefi, H.; Kimura, T. Strong Highly Anisotropic Magnetocellulose Nanocomposite Films Made by Chemical Peeling and in Situ Welding at the Interface Using an Ionic Liquid. ACS Appl. Mater. Interfaces 2014, 6, 8165-8172.

(25) Yousefi, H.; Mashkour, M.; Yousefi, R. Direct Solvent Nanowelding of Cellulose Fibers to Make All-Cellulose Nanocomposite. Cellulose 2015, 22, 1189-1200.

(26) Orelma, H.; Korpela, A.; Kunnari, V.; Harlin, A.; Suurnäkki, A. Improving the Mechanical Properties of CNF Films by NMMO Partial Dissolution with Hot Calender Activation. Cellulose 2017, 24, 1691-1704.

(27) Li, Y.; Wang, J.; Liu, X.; Zhang, S. Towards a Molecular Understanding of Cellulose Dissolution in Ionic Liquids: Anion/Cation Effect, Synergistic Mechanism and 
Physicochemical Aspects. Chem. Sci. 2018, 9, 4027-4043.

(28) Mohd, N.; Draman, S. F. S.; Salleh, M. S. N.; Yusof, N. B. Dissolution of Cellulose in Ionic Liquid: A Review. AIP Conf. Proc. 2017, 1809.

(29) King, A. W. T.; Asikkala, J.; Mutikainen, I.; Järvi, P.; Kilpeläinen, I. Distillable Acid-Base Conjugate Ionic Liquids for Cellulose Dissolution and Processing. Angew. Chemie - Int. Ed. 2011, 50, 6301-6305.

(30) Liu, H.; Sale, K. L.; Holmes, B. M.; Simmons, B. A.; Singh, S. Understanding the Interactions of Cellulose with ILs: MD Study. J. Phys. Chem. B 2010, 114, 4293-4301.

(31) Parthasarathi, R.; Balamurugan, K.; Shi, J.; Subramanian, V.; Simmons, B. A.; Singh, S. Theoretical Insights into the Role of Water in the Dissolution of Cellulose Using IL/Water Mixed Solvent Systems. J. Phys. Chem. B 2015, 119, 14339-14349.

(32) Liebert, T.; Heinze, T. Interaction of Ionic Liquids Wlth Polysaccharides 5. Solvents and Reaction Media for the Modification of Cellulose. BioResources 2008, 3, 576-601.

(33) Ostonen, A.; Bervas, J.; Uusi-Kyyny, P.; Alopaeus, V.; Zaitsau, D. H.; Emel'Yanenko, V. N.; Schick, C.; King, A. W. T.; Helminen, J.; Kilpeläinen, I.; Khachatrian, A. A.; Varfolomeev, M. A.; Verevkin, S. P. Experimental and Theoretical Thermodynamic Study of Distillable Ionic Liquid 1,5-Diazabicyclo[4.3.0]Non-5-Enium Acetate. Ind. Eng. Chem. Res. 2016, 55, 10445-10454.

(34) Duchemin, B.; P Mathew, A.; Oksman, K. Green Ionic Liquids for the Production of Fully Biobased and Biodegradable All-Cellulose Composites. In International Conference on Wood \& Biofiber Plastic Composites and Cellulose Nanocomposites; Forest Products Society, Ed.; Forest Products Society: Madison, Wisconsin, USA, 2010; p 35.

(35) Tanaka, A.; Khakalo, A.; Hauru, L.; Korpela, A.; Orelma, H. Conversion of Paper to Film 
by Ionic Liquids: Manufacturing Process and Properties. Cellulose 2018, 25, 6107-6119.

(36) Parviainen, A.; King, A. W. T.; Mutikainen, I.; Hummel, M.; Selg, C.; Hauru, L. K. J.; Sixta, H.; Kilpeläinen, I. Predicting Cellulose Solvating Capabilities of Acid-Base Conjugate Ionic Liquids. ChemSusChem 2013, 6, 2161-2169.

(37) Hsieh, M. C.; Koga, H.; Suganuma, K.; Nogi, M. Hazy Transparent Cellulose Nanopaper. Sci. Rep. 2017, 7, 1-7.

(38) Stepan, A. M.; Michud, A.; Hellstén, S.; Hummel, M.; Sixta, H. IONCELL-P\&F: Pulp Fractionation and Fiber Spinning with Ionic Liquids. Ind. Eng. Chem. Res. 2016, 55, 82258233.

(39) Holding, A. J.; Heikkilä, M.; Kilpeläinen, I.; King, A. W. T. Amphiphilic and PhaseSeparable Ionic Liquids for Biomass Processing. ChemSusChem 2014, 7, 1422-1434.

(40) Mazza, M.; Catana, D. A.; Vaca-Garcia, C.; Cecutti, C. Influence of Water on the Dissolution of Cellulose in Selected Ionic Liquids. Cellulose 2009, 16, 207-215.

(41) Hauru, L. K. J.; Hummel, M.; King, A. W. T.; Kilpeläinen, I.; Sixta, H. Role of Solvent Parameters in the Regeneration of Cellulose from Ionic Liquid Solutions. Biomacromolecules 2012, 13, 2896-2905.

(42) National Institutes of Health. ImageJ https://imagej.nih.gov/ij/index.html (accessed May 22, 2017).

(43) Ford, E. N. J.; Mendon, S. K.; Thames, S. F.; Rawlins, J. W. X-Ray Diffraction of Cotton Treated with Neutralized Vegetable Oil-Based Macromolecular Crosslinkers. J. Eng. Fiber. Fabr. 2010, 5, 10-20.

(44) Nam, S.; French, A. D.; Condon, B. D.; Concha, M. Segal Crystallinity Index Revisited by the Simulation of X-Ray Diffraction Patterns of Cotton Cellulose I $\beta$ and Cellulose II. 
Carbohydr. Polym. 2016, 135, 1-9.

(45) French, A. D. Idealized Powder Diffraction Patterns for Cellulose Polymorphs. Cellulose 2014, 21, 885-896.

(46) Wojdyr, M. Fityk: A General-Purpose Peak Fitting Program. J. Appl. Crystallogr. 2010, 43, $1126-1128$.

(47) Scherrer, P. Bestimmung Der Größe Und Der Inneren Struktur von Kolloidteilchen Mittels Röntgenstrahlen. Nachrichten von der Gesellschaft der Wissenschaften zu Göttingen, Math. Klasse 1918, 1918, 98-100.

(48) Segal, L.; Creely, J. J.; Martin, A. E.; Conrad, C. M. An Empirical Method for Estimating the Degree of Crystallinity of Native Cellulose Using the X-Ray Diffractometer. Text. Res. J. 1959, 29, 786-794.

(49) King, A. W. T.; Mäkelä, V.; Kedzior, S. A.; Laaksonen, T.; Partl, G. J.; Heikkinen, S.; Koskela, H.; Heikkinen, H. A.; Holding, A. J.; Cranston, E. D.; Kilpeläinen, I. Liquid-State NMR Analysis of Nanocelluloses. Biomacromolecules 2018, 19, 2708-2720.

(50) Bubalo, M. C.; Radošević, K.; Redovniković, I. R.; Slivac, I.; Srček, V. G. Toxicity Mechanisms of Ionic Liquids. Arh. Hig. Rada Toksikol. 2017, 68, 171-179.

(51) Ruokonen, S. K.; Sanwald, C.; Sundvik, M.; Polnick, S.; Vyavaharkar, K.; Duša, F.; Holding, A. J.; King, A. W. T.; Kilpeläinen, I.; Lämmerhofer, M.; Panula, P.; Wiedmer, SK. Effect of Ionic Liquids on Zebrafish (Danio Rerio) Viability, Behavior, and Histology; Correlation between Toxicity and Ionic Liquid Aggregation. Environ. Sci. Technol. 2016, $50(13), 7116-7125$.

(52) Ruokonen, S. K.; Sanwald, C.; Robciuc, A.; Hietala, S.; Rantamäki, A. H.; Witos, J.; King, A. W. T.; Lämmerhofer, M.; Wiedmer, S. K. Correlation between Ionic Liquid Cytotoxicity 
and Liposome-Ionic Liquid Interactions. Chem. - A Eur. J. 2018, 24, 2669-2680.

(53) Mikkola, S. K.; Robciuc, A.; Lokajová, J.; Holding, A. J.; Lämmerhofer, M.; Kilpeläinen, I.; Holopainen, J. M.; King, A. W. T.; Wiedmer, S. K. Impact of Amphiphilic BiomassDissolving Ionic Liquids on Biological Cells and Liposomes. Environ. Sci. Technol. 2015, $49,1870-1878$.

(54) Du, C.; Li, H.; Li, B.; Liu, M.; Zhan, H. Characteristics and Properties of Cellulose Nanofibers Prepared by TEMPO Oxidation of Corn Husk. BioResources 2016, 11, 52765284.

(55) Sharma, H. S. S.; Carmichael, E.; Muhamad, M.; McCall, D.; Andrews, F.; Lyons, G.; McRoberts, W. C.; Hornsby, P. R. Biorefining of Perennial Ryegrass for the Production of Nanofibrillated Cellulose. Rsc Adv. 2012, 2, 6424-6437.

(56) Kačuráková, M.; Mathlouthi, M. FTIR and Laser-Raman Spectra of Oligosaccharides in Water: Characterization of the Glycosidic Bond. Carbohydr. Res. 1996, 284, 145-157.

(57) Forziati, F. H.; Rowen, J. W. Effect of Changes in Crystalline Structure on the Infrared Absorption Spectrum of Cellulose. J. Res. Natl. Bur. Stand. (1934). 1951, 46, 38.

(58) Fitzpatrick, M.; Champagne, P.; Cunningham, M. F. Quantitative Determination of Cellulose Dissolved in 1-Ethyl-3- Methylimidazolium Acetate Using Partial Least Squares Regression on FTIR Spectra. Carbohydr. Polym. 2012, 87, 1124-1130.

(59) Ebner, G.; Schiehser, S.; Potthast, A.; Rosenau, T. Side Reaction of Cellulose with Common 1-Alkyl-3-Methylimidazolium-Based Ionic Liquids. Tetrahedron Lett. 2008, 49, 73227324.

(60) Schütz, C.; Sort, J.; Bacsik, Z.; Oliynyk, V.; Pellicer, E.; Fall, A.; Wågberg, L.; Berglund, L.; Bergström, L.; Salazar-Alvarez, G. Hard and Transparent Films Formed by 
Nanocellulose-TiO2 Nanoparticle Hybrids. PLoS One 2012, 7, 1-8.

(61) Krug, H.; Schmidt, H. Organic-Inorganic Nanocomposites for Micro Optical Applications. In Hybrid Nanocomposites for Nanotechnology Electronic, Optical, Magnetic and Biomedical Applications; Merhari, L., Ed.; New York, USA, 2009; Vol. 18, pp 1125-1134.

(62) Isik, M.; Sardon, H.; Mecerreyes, D. Ionic Liquids and Cellulose: Dissolution, Chemical Modification and Preparation of New Cellulosic Materials. Int. J. Mol. Sci. 2014, 15, $11922-11940$.

(63) Jiang, Y.; Song, Y.; Miao, M.; Cao, S.; Feng, X.; Fang, J.; Shi, L. Transparent Nanocellulose Hybrid Films Functionalized with ZnO Nanostructures for UV-Blocking. J. Mater. Chem. C 2015, 3, 6717-6724.

(64) Majumdar, S.; Kumar, D. Acrylate Grafted Dehydrated Castor Oil. 1998, 70, 27-33.

(65) Pantani, R.; Turng, L. S. Manufacturing of Advanced Biodegradable Polymeric Components. Journal of Applied Polymer Science. 2015. DOI: 10.1002/APP.42889

(66) Abdulkhani, A.; Hojati Marvast, E.; Ashori, A.; Hamzeh, Y.; Karimi, A. N. Preparation of Cellulose/Polyvinyl Alcohol Biocomposite Films Using 1-n-Butyl-3-Methylimidazolium Chloride. Int. J. Biol. Macromol. 2013, 62, 379-386.

(67) Xue, Z.; Zhao, X.; Sun, R. C.; Mu, T. Biomass-Derived $\gamma$-Valerolactone-Based Solvent Systems for Highly Efficient Dissolution of Various Lignins: Dissolution Behavior and Mechanism Study. ACS Sustain. Chem. Eng. 2016, 4, 3864-3870.

(68) Lê, H. Q.; Sixta, H.; Hummel, M. Ionic Liquids and Gamma-Valerolactone as Case Studies for Green Solvents in the Deconstruction and Refining of Biomass. Curr. Opin. Green Sustain. Chem. 2018. https://doi.org/10.1016/j.cogsc.2018.11.009.

(69) Dufresne, A. Nanocellulose: A New Ageless Bionanomaterial. Mater. Today 2013, 16, 220- 
227.

(70) Nogi, M.; Handa, K.; Nakagaito, A. N.; Yano, H. Optically Transparent Bionanofiber Composites with Low Sensitivity to Refractive Index of the Polymer Matrix. Appl. Phys. Lett. 2005, 87, 1-3.

(71) Park, S.; Baker, J. O.; Himmel, M. E.; Parilla, P. a; Johnson, D. K. Cellulose Crystallinity Index: Measurement Techniques and Their Impact on Interpreting Cellulase Performance. Biotechnol. Biofuels 2010, 3, 10. 


\section{For Table of Contents Use Only}

\section{Solvent welding and imprinting cellulose nanofiber}

\section{films using ionic liquids}

Guillermo Reyes $^{*}+$, Maryam Borghei ${ }^{\text {L }}$, Alistair W. T. King ${ }^{\S}$, Johanna Lahti ${ }^{\ddagger}$, Orlando J. Rojas $^{\ddagger}$.

† Departamento de Ingeniería en Maderas DIMAD, Universidad del Bío-Bío, Av. Collao 1202, Casilla 5-C, Concepción, Chile

\$, ${ }^{\mathrm{B}}$ Biobased Colloids and Materials, Department of Bioproducts and Biosystems, School of Chemical Engineering, Aalto University, Espoo, Finland

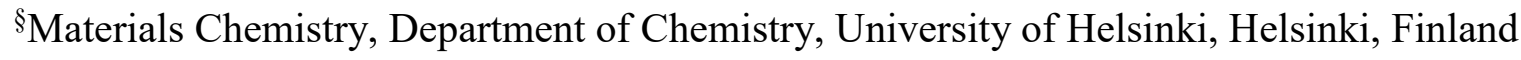

†Tampere University of Technology, Tampere, Finland

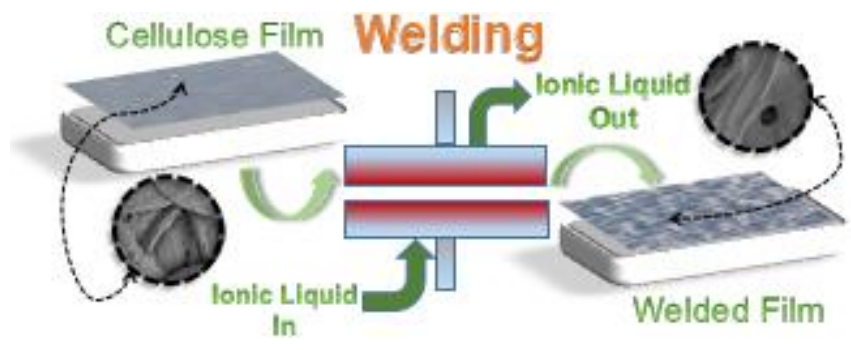

